\title{
Aerosol water parameterisation: a single parameter framework
}

\author{
Swen Metzger ${ }^{1,2,3}$, Benedikt Steil ${ }^{2}$, Mohamed Abdelkader $^{2}$, Klaus Klingmüller $^{2}, \mathbf{L i ~ X u}{ }^{4}$, Joyce E. Penner $^{5}$, \\ Christos Fountoukis $^{5,1}$, Athanasios Nenes ${ }^{6,7,8}$, and Jos Lelieveld ${ }^{1,2}$ \\ ${ }^{1}$ The Cyprus Institute, Nicosia, Cyprus \\ ${ }^{2}$ Max Planck Institute for Chemistry, Mainz, Germany \\ ${ }^{3}$ Eco-Serve, Freiburg, Germany \\ ${ }^{4}$ Department of Earth System Science, University of California, Irvine, USA \\ ${ }^{5}$ Atmospheric Science, University of Michigan, Ann Arbor, Michigan, USA \\ ${ }^{6}$ Institute of Chemical Engineering Sciences, Foundation for Research and Technology Hellas, Patras, Greece \\ ${ }^{7}$ Schools of Earth and Atmospheric Sciences and Chemical and Biomolecular Engineering, Georgia Institute of Technology, \\ Atlanta, GA, USA \\ ${ }^{8}$ Institute of Environmental Research and Sustainable Development, \\ National Observatory of Athens, Palea Penteli, Greece
}

Correspondence to: Swen Metzger (s.metzger@cyi.ac.cy)

Received: 22 October 2015 - Published in Atmos. Chem. Phys. Discuss.: 27 November 2015

Revised: 20 April 2016 - Accepted: 20 May 2016 - Published: 10 June 2016

\begin{abstract}
We introduce a framework to efficiently parameterise the aerosol water uptake for mixtures of semi-volatile and non-volatile compounds, based on the coefficient, $v_{i}$. This solute-specific coefficient was introduced in Metzger et al. (2012) to accurately parameterise the single solution hygroscopic growth, considering the Kelvin effect - accounting for the water uptake of concentrated nanometer-sized particles up to dilute solutions, i.e. from the compounds relative humidity of deliquescence (RHD) up to supersaturation (Köhler theory). Here we extend the $v_{i}$ parameterisation from single to mixed solutions. We evaluate our framework at various levels of complexity, by considering the full gas-liquid-solid partitioning for a comprehensive comparison with reference calculations using the E-AIM, EQUISOLV II and ISORROPIA II models as well as textbook examples. We apply our parameterisation in the EQuilibrium Simplified Aerosol Model V4 (EQSAM4clim) for climate simulations, implemented in a box model and in the global chemistry-climate model EMAC. Our results show (i) that the $v_{i}$ approach enables one to analytically solve the entire gas-liquid-solid partitioning and the mixed solution water uptake with sufficient accuracy, (ii) that ammonium sulfate mixtures can be solved with a simple method, e.g. pure ammonium nitrate and mixed ammonium nitrate and (iii) that the aerosol optical depth (AOD) simulations are
\end{abstract}

in close agreement with remote sensing observations for the year 2005. Long-term evaluation of the EMAC results based on EQSAM4clim and ISORROPIA II will be presented separately.

\section{Introduction}

The most comprehensive description of aerosol composition and hygroscopic growth is provided by models that calculate the full gas-liquid-solid partitioning, i.e. the composition and state of the ion-pairs over the wide range of temperatures and relative humidities from the surface in the tropics to the winter polar stratosphere. Since thermodynamic equilibrium is the final state of kinetic processes, many modelling approaches assume equilibrium, which is reasonable if the atmospheric processes that lead toward it are fast compared to those that lead away from it (Wexler and Potukuchi, 1998).

To calculate the multiphase partitioning, composition and associated water uptake of multicomponent atmospheric aerosols, various equilibrium models (EQMs) have been developed over the past decades including: EQUIL (Bassett and Seinfeld, 1983), KEQUIL (Bassett and Seinfeld, 1984), MARS (Saxena et al., 1986), MARS-A (Binkowski and Shankar, 1995), SEQUI- 
LIB (Pilinis and Seinfeld, 1987), AIM (Wexler and Seinfeld, 1991), SCAPE (Kim et al., 1993a, b; Kim and Seinfeld, 1995), SCAPE2 (Meng et al., 1995), EQUISOLV (Jacobson et al., 1996), ISORROPIA (Nenes et al., 1998, 1999), EQUISOLV II (Jacobson, 1999), GFEMN (Ansari and Pandis, 1999, 2000), EQSAM (Metzger et al., 2002a, b), AIM2 and E-AIM (Wexler and Clegg, 2002), HETV (Makar et al., 2003), ADDEM (Topping et al., 2005a, b), MESA (Zaveri, 2005), EQSAM2 (Metzger et al., 2006), UHAERO (Amundson et al., 2006), ISORROPIA II (Fountoukis and Nenes, 2007), EQSAM3 (Metzger and Lelieveld, 2007), UCD (Zhang and Wexler, 2008), AIOMFAC (Zuend et al., 2011) and EQSAM4clim (this work).

These EQMs are often embedded in aerosol dynamical models (e.g. Pilinis et al., 2000), but the gas-aerosol partitioning and especially the associated water uptake controls the aerosol size distribution, if treated explicitly, which makes the development of EQMs most critical. As a consequence, EQMs vary in the degree of complexity and computational approaches, while almost all EQMs are computationally expensive, due to the complexity of the underlying multicomponent and multiphase thermodynamics. Either numerical accuracy has higher priority than computational efficiency (i.e. iterations to reach equilibrium are extensive), or the computational approaches are comprehensive, often both apply. Despite the large efforts, computational efficiency, especially if combined with accuracy and flexibility regarding the number of chemical compounds that can be considered, remains a challenge, which is especially relevant for global atmospheric aerosol-chemistry and climate modelling.

To meet this challenge we introduce in Sect. 2 an unique single parameter framework, which is subsequently applied in Sect. 3. Our framework allows one to efficiently parameterise the aerosol water uptake for mixtures of semi-volatile and non-volatile compounds, being entirely based on the single solute-specific coefficient introduced in Metzger et al. (2012). Additional results and textbook examples of Seinfeld and Pandis (2006) are presented in the Supplement. We conclude with Sect. 4.

\section{Mixed solution parameterisation framework}

We introduce a mixed solution parameterisation framework to efficiently calculate the aerosol water uptake for mixtures of semi-volatile and non-volatile compounds with the constraint of using only one parameter, i.e. $v_{i}$. The solutespecific coefficient $v_{i}$ was introduced in Metzger et al. (2012) - referred to in the following as M2012 - to accurately parameterise the single solution hygroscopic growth, also considering the Kelvin effect. M2012 have shown that the $v_{i}$ approach is valid for a wide range of atmospheric conditions. To investigate the potential of the $v_{i}$ approach with respect to mixtures of salt compounds, we extend in this work the $v_{i}$ parameterisations from single to mixed solutions. Since computational efficiency is a requirement for our parameterisation framework, we minimise the overall computational burden by a set of key-constraints:

1. Solving the multicomponent and multiphase partitioning analytically, by using a consistent set of equations, based on one compound-specific single solute coefficient, $v_{i}[-]$. This set of equations includes the solute molality, $\mu_{\mathrm{s}}\left[\mathrm{mol}\left(\right.\right.$ solute) $\left.\mathrm{kg}^{-1}\left(\mathrm{H}_{2} \mathrm{O}\right)\right]$, and its equivalent expression in terms of the mass fraction solubility, $\chi_{\mathrm{s}}[-]$. Both are the essential thermodynamic properties in our framework and only depend on $v_{i}$; the temperature $(T)$, relative humidity $(\mathrm{RH})$ and the particle dry diameter $\left(D_{\mathrm{s}}\right)$ are given;

2. Breaking down the complexity of aerosol thermodynamics as much as possible, without the loss of crucial information and critical numerical accuracy, by using chemical domains with a neutralisation order for all salt compounds listed in Table 1;

3. Minimising the dependencies on the required thermodynamic data by using a pre-determined $v_{i}$ coefficient for each electrolyte listed in Table 1;

4. Assuming $v_{i}$, constant for the entire range of water activity, $a_{\mathrm{w}}$.

The relevant single solute equations (of M2012) are summarised in Appendix A. The mixed solution parameterisation framework has been determined by a multi-functional fitting, limited to one parameter per compound, to match the results of ISORROPIA II. The multiphase and multicomponent thermodynamic system has an analytical solution when our consistent set of analytical equations and the $v_{i}$ coefficient of M2012 are used. Consequently, our parameterisation framework has a similar applicability as ISORROPIA II.

\subsection{Pre-determined $v_{i}$}

M2012 have detailed that a (unitless) single solute coefficient, i.e. $v_{i}[-]$, can be accurately deduced from one reference data pair of solute molality, $\mu_{\mathrm{s}}$, and the corresponding water activity, $a_{\mathrm{w}}[-]$. We use a data pair at solute saturation to pre-determine $v_{i}$, since measurements are available for all major salt compounds that are of interest in atmospheric aerosol modelling. For the salt compounds listed in Table 1 we use the mass fraction solubility, $w_{\mathrm{s}}[-]$, which is an equivalent expression of the saturation molality, $\mu_{\mathrm{s} \text {, sat }}$. For the corresponding $a_{\mathrm{w}}$, we use the available relative humidity of deliquescence (RHD) values and obtain $v_{i}$ by solving Eq. (5b) of M2012 with a root finding method (bisection). To be consistent with ISORROPIA II, here we determine $v_{i}$ from $w_{\mathrm{s}}$ and RHD data at temperature $T_{\mathrm{O}}=298$ [K]. The water activity data used by ISORROPIA II (and other EQMs) are tabulated only for room temperature. We therefore do not consider the $T$ dependency of $v_{i}$ in this work. 
Table 1. Thermodynamic data (Sect. 2.1): stoichiometric coefficient $v_{\mathrm{S}}[-]$, the ion-pair charge $Z_{\mathrm{S}}[-]$, the single solute parameter $v_{i}[-]$, the mass fraction solubility in percent $W_{\mathrm{S}}[\%]\left(w_{\mathrm{S}}=W_{\mathrm{S}} / 100\right)$, the molar masses $M_{\mathrm{S}}\left[\mathrm{kg} \mathrm{mol}^{-1}\right]$, the densities $D_{\mathrm{S}}\left[\mathrm{kg} \mathrm{m}^{-3}\right], \mathrm{RHD}\left(T_{\mathrm{O}}\right)[-]$ at reference temperature $T_{\mathrm{O}}=298.15[\mathrm{~K}]$, and the corresponding temperature coefficients, $T_{\text {coef(RHD) }}[-]$. The $v_{i}$ values have been obtained from the RHD and $W_{\mathrm{S}}$ values (at $T_{\mathrm{O}}=298[\mathrm{~K}]$ ) following the method described in Metzger et al. (2012). The RHD values are taken from Fountoukis and Nenes (2007); the $W_{\mathrm{S}}$ and all other values are taken from the Handbook of Chemistry and Physics (Lide, 2005).

\begin{tabular}{|c|c|c|c|c|c|}
\hline Species 01-05 & $\mathrm{H}_{2} \mathrm{O}$ & $\mathrm{H}_{2} \mathrm{SO}_{4}$ & $\mathrm{HNO}_{3}$ & $\mathrm{HCl}$ & $\mathrm{NH}_{3}$ \\
\hline$v_{\mathrm{s}} \mid Z_{\mathrm{s}}$ & $2 \mid 1$ & 312 & 211 & $2 \mid 1$ & $1 \mid 1$ \\
\hline$v_{i}$ & - & - & - & - & - \\
\hline$W_{\mathrm{S}}$ & - & - & - & - & - \\
\hline$M_{\mathrm{S}}$ & 0.018020 & 0.098090 & 0.063020 & 0.036460 & 0.017040 \\
\hline$D_{\mathrm{S}}$ & 997 & 1830 & 1513 & 1490 & 696 \\
\hline RHD & - & - & - & - & - \\
\hline$T_{\text {coef }}$ & - & - & - & - & - \\
\hline Species 06-10 & $\left(\mathrm{NH}_{4}\right)_{3} \mathrm{H}\left(\mathrm{SO}_{4}\right)_{2}$ & $\left(\mathrm{NH}_{4}\right)_{2} \mathrm{SO}_{4}$ & $\mathrm{NH}_{4} \mathrm{HSO}_{4}$ & $\mathrm{NH}_{4} \mathrm{NO}_{3}$ & $\mathrm{NH}_{4} \mathrm{Cl}$ \\
\hline$v_{\mathrm{s}} \mid Z_{\mathrm{s}}$ & 513 & $3 \mid 2$ & 211 & $2 \mid 1$ & $2 \mid 1$ \\
\hline$v_{i}$ & 1.616356 & 1.274822 & 1.253573 & 1.051480 & 1.243054 \\
\hline$W_{\mathrm{s}}$ & 53.30 & 43.31 & 76.00 & 68.05 & 28.34 \\
\hline$M_{\mathrm{S}}$ & 0.247300 & 0.132170 & 0.115130 & 0.080060 & 0.053500 \\
\hline$D_{\mathrm{S}}$ & 1775 & 1770 & 1780 & 1720 & 1519 \\
\hline RHD & 0.6900 & 0.7997 & 0.4000 & 0.6183 & 0.7710 \\
\hline$T_{\text {coef }}$ & 186.00 & 80.00 & 384.00 & 852.00 & 239.00 \\
\hline Species $11-15$ & $\mathrm{Na}_{3} \mathrm{H}\left(\mathrm{SO}_{4}\right)_{2}$ & $\mathrm{Na}_{2} \mathrm{SO}_{4}$ & $\mathrm{NaHSO}_{4}$ & $\mathrm{NaNO}_{3}$ & $\mathrm{NaCl}$ \\
\hline$v_{\mathrm{s}} \mid Z_{\mathrm{s}}$ & 513 & 312 & 211 & $2 \mid 1$ & $2 \mid 1$ \\
\hline$v_{i}$ & - & 1.278762 & 1.293906 & 1.160345 & 1.358377 \\
\hline$W_{\mathrm{s}}$ & - & 21.94 & 66.18 & 47.70 & 26.47 \\
\hline$M_{\mathrm{S}}$ & 0.262120 & 0.142050 & 0.120070 & 0.085000 & 0.058440 \\
\hline$D_{\mathrm{s}}$ & 2565 & 2700 & 2430 & 2260 & 2170 \\
\hline RHD & - & 0.9300 & 0.5200 & 0.7379 & 0.7528 \\
\hline$T_{\text {coef }}$ & - & 80.00 & -45.00 & 304.00 & 25.00 \\
\hline Species 16-20 & $\mathrm{K}_{3} \mathrm{H}\left(\mathrm{SO}_{4}\right)_{2}$ & $\mathrm{~K}_{2} \mathrm{SO}_{4}$ & $\mathrm{KHSO}_{4}$ & $\mathrm{KNO}_{3}$ & $\mathrm{KCl}$ \\
\hline$v_{\mathrm{s}} \mid Z_{\mathrm{s}}$ & 513 & 312 & $2 \mid 1$ & $2 \mid 1$ & $2 \mid 1$ \\
\hline$v_{i}$ & - & 1.286445 & 1.308499 & 1.014102 & 1.256989 \\
\hline$W_{\mathrm{S}}$ & - & 10.71 & 33.60 & 27.69 & 26.23 \\
\hline$M_{\mathrm{S}}$ & 0.310444 & 0.174266 & 0.136178 & 0.101108 & 0.074548 \\
\hline$D_{\mathrm{S}}$ & 2490 & 2660 & 2320 & 2110 & 1988 \\
\hline RHD & - & 0.9750 & 0.8600 & 0.9248 & 0.8426 \\
\hline$T_{\text {coef }}$ & - & 35.60 & 0 & 0 & 159.00 \\
\hline Species 21-25 & $\mathrm{n} / \mathrm{a}$ & $\mathrm{CaSO}_{4}$ & $\mathrm{n} / \mathrm{a}$ & $\mathrm{Ca}\left(\mathrm{NO}_{3}\right)_{2}$ & $\mathrm{Ca}(\mathrm{Cl})_{2}$ \\
\hline$v_{\mathrm{s}} \mid Z_{\mathrm{s}}$ & $-1-$ & $2 \mid 2$ & $-1-$ & 312 & 312 \\
\hline$v_{i}$ & - & 1.271828 & - & 1.586562 & 2.024869 \\
\hline$W_{\mathrm{s}}$ & - & 0.21 & - & 59.02 & 44.84 \\
\hline$M_{\mathrm{S}}$ & - & 0.136150 & - & 0.164100 & 0.110980 \\
\hline$D_{\mathrm{s}}$ & - & 2960 & - & 2500 & 2150 \\
\hline RHD & - & 0.9900 & - & 0.4906 & 0.2830 \\
\hline$T_{\text {coef }}$ & - & 0 & - & 509.40 & 551.10 \\
\hline Species $25-30$ & $\mathrm{n} / \mathrm{a}$ & $\mathrm{MgSO}_{4}$ & $\mathrm{n} / \mathrm{a}$ & $\mathrm{Mg}\left(\mathrm{NO}_{3}\right)_{2}$ & $\mathrm{Mg}(\mathrm{Cl})_{2}$ \\
\hline$v_{\mathrm{s}} \mid Z_{\mathrm{s}}$ & $-1-$ & 212 & $-1-$ & 312 & 312 \\
\hline$v_{i}$ & - & 1.435281 & - & 1.878693 & 2.107772 \\
\hline$W_{\mathrm{s}}$ & - & 26.31 & - & 41.59 & 35.90 \\
\hline$M_{\mathrm{S}}$ & - & 0.120375 & - & 0.148325 & 0.095205 \\
\hline$D_{\mathrm{s}}$ & - & 2660 & - & 2300 & 2325 \\
\hline RHD & - & 0.8613 & - & 0.5400 & 0.3284 \\
\hline$T_{\text {coef }}$ & - & -714.45 & - & 230.20 & 42.23 \\
\hline
\end{tabular}


Table 2. Chemical domains (introduced in Sect. 2.2).

\begin{tabular}{llllr}
\hline D4 & SULFURIC ACID ONLY & tCAT $<$ MIN & AND & tHSO $_{4} \geq \mathrm{MIN}$ \\
D3 & SULFATE VERY RICH & tCAT $\geq$ MIN & AND & tCAT $<$ tHSO $_{4}$ \\
D2 & SULFATE RICH & tCAT $\geq \mathrm{tHSO}_{4}$ & AND & tCAT $<\mathrm{tSO}_{4}$ \\
D1 & SULFATE NEUTRAL & tCAT $\geq \mathrm{tSO}_{4}$ & & \\
\hline
\end{tabular}

Table 1 lists the pre-calculated $v_{i}$ values for each salt compound considered, together with the required thermodynamic data: Stoichiometric coefficient $v_{\mathrm{s}}[-]$, the ionpair charge $Z_{\mathrm{s}}[-]$, the single solute parameter $v_{i}[-]$, the mass fraction solubility in percent $W_{\mathrm{s}}[\%]\left(w_{\mathrm{s}}=W_{\mathrm{s}} / 100\right)$, the molar masses $M_{\mathrm{s}}\left[\mathrm{kg} \mathrm{mol}^{-1}\right]$, the densities $D_{\mathrm{s}}\left[\mathrm{kg} \mathrm{m}^{-3}\right]$, $\operatorname{RHD}\left(T_{\mathrm{o}}\right)[-]$ at reference temperature $T_{\mathrm{o}}=298.15[\mathrm{~K}]$ and the corresponding temperature coefficients, $T_{\text {coef(RHD) }}[-]$. The RHD values are taken from Fountoukis and Nenes (2007); the other values of Table 1 are taken from the Handbook of Chemistry and Physics (Lide, 2005).

\subsection{Chemical domains}

To break down the complexity of aerosol thermodynamics as much as possible, we minimise the number of chemical compounds and equilibrium reactions that have to be considered. Following the original EQSAM approach (Metzger et al., 2002a), we define chemical domains with a sub-set of neutralisation reactions that are considered for a given $T, \mathrm{RH}$ and input concentrations (total of aerosol cations/anions and precursor gases), with all concentration units in $\left[\mathrm{mol} \mathrm{m}^{-3}\right.$ (air)]. Our domain definition is listed in Table 2 and applied in our mixed solution framework with if-else logic and top-down approach. The potential aerosol neutralisation levels depend on the input concentration ratio of total cations, tCAT. The cations are balanced against the total sulfate anions, for which we consider, for sulfate-rich cases, the total sulfates as bi-sulfate, $\mathrm{tHSO}_{4}$, or for sulfate-poor cases as total sulfate, $\mathrm{tSO}_{4}$. In any case, these totals " $\mathrm{t}$ " need to exceed a threshold, $\mathrm{MIN}=1 \times 10^{-15}\left[\mathrm{~mol} \mathrm{~m}^{-3}\right.$ (air)]; below the computations are neglected for a given domain. Our definition of totals is given by our domain classification (Table 2), implicitly taking into account the maximum neutralisation level that is theoretically possible for each domain:

$$
\begin{aligned}
& -\mathrm{tSO}_{4}=\sum\left(1 \cdot \mathrm{HSO}_{4}^{-}+2 \cdot \mathrm{SO}_{4}^{2-}\right) \\
& -\mathrm{tHSO}_{4}=\sum\left(1 \cdot \mathrm{HSO}_{4}^{-}+1 \cdot \mathrm{SO}_{4}^{2-}\right) \\
& -\mathrm{tCAT}= \\
& \quad \sum\left(2 \cdot \mathrm{Ca}^{2+}+2 \cdot \mathrm{Mg}^{2+}+1 \cdot \mathrm{Na}^{+}+1 \cdot \mathrm{K}^{+}+1 \cdot \mathrm{NH}_{4}^{+}\right) .
\end{aligned}
$$

The domain definition (Table 2) is subsequently used to define the neutralisation reaction order (see Sect. 2.3). The two semi-volatile compounds listed in Table $1, \mathrm{NH}_{4} \mathrm{NO}_{3}$ and $\mathrm{NH}_{4} \mathrm{Cl}$, are considered in our approach only in the sulfate neutral (D1) domain. On the other hand, bi-sulfate is taken into account only for the sulfate-rich (D2) and very-rich (D3) cases, while free sulfuric acid is considered only for the unneutralised sulfate case (D4).

\subsection{Domain-dependent neutralisation reaction order}

To avoid the numerical minimisation of the Gibbs free energy, which is required to obtain the equilibrium composition of mixed solutions (Seinfeld and Pandis, 2006), we define for each domain (Table 2) a neutralisation reaction order (NRO), which can practically be considered as the salting-out effect of salt solutes (Metzger and Lelieveld, 2007). For this work, we rank the cations and anions according to their preferred neutralisation reaction by

$$
\begin{aligned}
& \text { - Anions: } \mathrm{SO}_{4}^{2-}-\mathrm{HSO}_{4}^{-}-\mathrm{NO}_{3}^{-}-\mathrm{Cl}^{-} \\
& \text {- Cations: } \mathrm{Ca}^{2+}-\mathrm{Mg}^{2+}-\mathrm{K}^{+}-\mathrm{Na}^{+}-\mathrm{NH}_{4}^{+}-\mathrm{H}^{+},
\end{aligned}
$$

which yields the NRO listed in Table 3. The ordering is based on numerous modelling studies, both extensive boxmodelling comparisons (Metzger et al., 2002a, 2006, 2012) and global applications (Metzger et al., 1999, 2002b; Metzger and Lelieveld, 2007). Note that we have constrained the ordering for this work to achieve the closet agreement with ISORROPIA II for two reasons: (1) ISORROPIA II is currently the only EQM that is widely applied in global modelling; (2) and it also considers the mineral cations $\mathrm{Ca}^{2+}$, $\mathrm{Mg}^{2+}$ and $\mathrm{K}^{+}$.

To solve the mixed solution framework we apply the NRO to balance cation-anion pairs that have a non-zero ion-ion product. Within a chemical domain (Table 2), the electrolyte compounds listed in Table 3 are subsequently formed for non-zero ion-ion product, until all cation-anion pairs are paired, or either all cations or anions are fully neutralised. To analytically solve the entire gas-liquid-solid partitioning, we consider at this stage all electrolytes in solution (computing totals of gas and ions). The gas-solid and gas-liquid partitioning of semi-volatile compounds, the liquid-solid partitioning and the water uptake are determined in that order in subsequent and independent computational steps (Sect. S2 in the Supplement).

\subsection{Treatment of semi-volatile compounds}

Table 1 includes two semi-volatile compounds that exhibit the gas-liquid-solid partitioning, i.e. ammonium nitrate, $\mathrm{NH}_{4} \mathrm{NO}_{3}$, and ammonium chloride, $\mathrm{NH}_{4} \mathrm{Cl}$. Both are allowed in our framework only in D1, provided that a surplus ammonium, $\mathrm{NH}_{4}^{+}$, is available. Our implicit assumption 
Table 3. Neutralisation reaction order for Table 2 (introduced in Sect. 2.3).

\begin{tabular}{lll}
\hline D1 & i.e. Sulfate neutral \\
\hline 1. $\mathrm{CaSO}_{4}$ & 2. $\mathrm{MgSO}_{4}$ & 3. $\mathrm{K}_{2} \mathrm{SO}_{4}$ \\
4. $\mathrm{Na}_{2} \mathrm{SO}_{4}$ & 5. $\left(\mathrm{NH}_{4}\right)_{2} \mathrm{SO}_{4}$ & 6. $\mathrm{Ca}\left(\mathrm{NO}_{3}\right)_{2}$ \\
7. $\mathrm{Mg}\left(\mathrm{NO}_{3}\right)_{2}$ & 8. $\mathrm{KNO}_{3}$ & 9. $\mathrm{NaNO}$ \\
10. $\mathrm{NH}_{4} \mathrm{NO}_{3}$ & 11. $\mathrm{Ca}(\mathrm{Cl})_{2}$ & 12. $\mathrm{Mg}(\mathrm{Cl})_{2}$ \\
13. $\mathrm{KCl}$ & 14. NaCl & 15. $\mathrm{NH}_{4} \mathrm{Cl}$ \\
\hline $\mathrm{D} 2$ & i.e. Sulfate rich \\
\hline 1. $\mathrm{CaSO}_{4}$ & 2. $\mathrm{MgSO}_{4}$ & 3. $\mathrm{K}_{2} \mathrm{SO}_{4}$ \\
4. $\mathrm{KHSO}_{4}$ & 5. $\mathrm{Na}_{2} \mathrm{SO}_{4}$ & 6. $\mathrm{NaHSO}_{4}$ \\
7. $\left(\mathrm{NH}_{4}\right)_{2} \mathrm{SO}_{4}$ & 8. $\mathrm{NH}_{4} \mathrm{HSO}_{4}$ & \\
\hline D3 & i.e. $\mathrm{Sulfate} \mathrm{very} \mathrm{rich}$ \\
\hline 1. $\mathrm{CaSO}_{4}$ & 2. $\mathrm{MgSO}_{4}$ & 3. $\mathrm{KHSO}_{4}$ \\
4. $\mathrm{NaHSO}_{4}$ & 5. $\mathrm{NH}_{4} \mathrm{HSO}$ & \\
\hline D4 & i.e. Sulfuric acid \\
\hline 1. $\mathrm{H}_{2} \mathrm{SO}_{4}$ & & \\
\hline
\end{tabular}

is that all sulfates are neutralised first through the reactions with cations (Sect. 2.3). Only excess ammonium may further neutralise anions, nitrate, $\mathrm{NO}_{3}^{-}$and/or chloride, $\mathrm{Cl}^{-}$. Thus, semi-volatile compounds can only partition into the particles, if the concentration product exceeds a threshold that is given by the temperature- and humidity-dependent equilibrium dissociation constant, $K_{\mathrm{p}}(T, \mathrm{RH})$. The equilibrium partitioning is detailed in Seinfeld and Pandis (2006) - hereafter referred to as SP2006 (Sect. 10.4.3 ff).

\subsubsection{RH $<$ RHD - pure and mixed compounds}

When the RH is below the RHD and the partial pressure product of gaseous $(\mathrm{g})$ ammonia, $\mathrm{NH}_{3}(\mathrm{~g})$, and nitric acid, $\mathrm{HNO}_{3}(\mathrm{~g})$, with units either in [ppbv] or $\left[\mathrm{mol} \mathrm{m}^{-3}\right.$ (air)], equals or exceeds the temperature-dependent equilibrium dissociation constant, $K_{\mathrm{p}}(T)$, solid (s) ammonium nitrate (AN), $\mathrm{NH}_{4} \mathrm{NO}_{3}(\mathrm{~s})$, is assumed to be formed instantaneously:

$$
\mathrm{NH}_{3}(\mathrm{~g})+\mathrm{HNO}_{3}(\mathrm{~g}) \Longleftrightarrow \mathrm{NH}_{4} \mathrm{NO}_{3}(\mathrm{~s})
$$

EQ: $\left[\mathrm{NH}_{3}(\mathrm{~g})\right] \cdot\left[\mathrm{HNO}_{3}(\mathrm{~g})\right]=K_{\mathrm{p}, \mathrm{AN}}(T)$.

For Reaction (R1) the equilibrium concentration of solid ammonium nitrate can be analytically computed from the gaseous concentrations by solving a quadratic equation - for our examples in the Supplement we use [ppbv]. We compute the temperature dependency of the equilibrium dissociation constants, $K_{\mathrm{p}}(T)$, following Fountoukis and Nenes (2007):

$$
\begin{aligned}
& K_{\mathrm{p}}(T)=K_{\mathrm{p}}^{\mathrm{o}} \times \exp [a \\
& \left.\quad \times\left(T_{\mathrm{o}} / T-1\right)+b \times\left(1+\ln \left(T_{\mathrm{o}} / T\right)-T_{\mathrm{o}} / T\right)\right],
\end{aligned}
$$

Table 4. Equilibrium dissociation constants $\left[\mathrm{ppbv}^{2}\right]$ and $T$ coefficients [-]; from Fountoukis and Nenes (2007).

\begin{tabular}{llll}
\hline $\mathrm{NH}_{4} \mathrm{NO}_{3}$ & $K_{\mathrm{p}}^{\mathrm{o}}=57.46$ & $a=-74.38$ & $b=6.120$ \\
$\mathrm{NH}_{4} \mathrm{Cl}$ & $K_{\mathrm{p}}^{\mathrm{O}}=1.086$ & $a=-71.00$ & $b=2.400$
\end{tabular}

where $T$ and $T_{\mathrm{o}}=298.15 \mathrm{~K}$, the ambient temperature and reference temperature, respectively. The $K_{\mathrm{p}}^{\mathrm{o}}\left(T_{\mathrm{o}}\right)$ values are given in Table 4 in $\left[\mathrm{ppbv}^{2}\right]$ for $T_{\mathrm{o}}$ and reference pressure, $P_{\mathrm{o}}=1[\mathrm{~atm}]=101325[\mathrm{~Pa}]$, together with the dimensionless temperature coefficients, $a$ and $b[-]$. For applications on a mole basis (e.g. for EQSAM4clim), $K_{\mathrm{p}}(T)\left[\mathrm{ppbv}^{2}\right]$ can be converted to $\left[\left(\mathrm{molm}^{-3}(\text { air })\right)^{2}\right]$, using $K_{\mathrm{p}, \operatorname{mol}}(T)=$ $K_{\mathrm{p}}(T) /(R / P \times T)^{2}$, with $R=8.314409\left[\mathrm{~Pa} \mathrm{~m}^{3} \mathrm{~mol}^{-1} \mathrm{~K}^{-1}\right]$ the gas constant and $P=101325[\mathrm{~Pa}] \quad\left(R / P_{\mathrm{o}} \times T_{\mathrm{o}}=\right.$ $\left.24.465\left[\mathrm{~L} \mathrm{~mol}^{-1}\right]\right)$.

The equilibrium dissociation constant of $\mathrm{NH}_{4} \mathrm{NO}_{3}$ is sensitive to temperature changes and varies over more than 2 orders of magnitude for typical ambient conditions. This is illustrated in Fig. 10.19 of SP2006, which we recommend to the reader for a detailed discussion. For comparison, Fig. 1 shows the same $K_{\mathrm{p}, \mathrm{AN}}$ values as a function of $T$ at $\mathrm{RH}<\mathrm{RHD}$ for the EQSAM4clim and ISORROPIA II applications. Although the results are similar, those of SP2006 are slightly lower since their values are obtained from a slightly different equation, i.e. $K_{\mathrm{p}, \mathrm{AN}}(T)=\exp (84.6-24220 / T-$ $\left.6.1 \times \ln \left(T / T_{\mathrm{o}}\right)\right)-$ see Eq. (10.91) of SP2006 (respectively Eq. 9.91 and Fig. 9.19 of Seinfeld and Pandis, 1998).

Note that Reaction (R1) applies to the gas-aerosol partitioning over dry aerosols - pure $\mathrm{NH}_{4} \mathrm{NO}_{3}(\mathrm{~s})$, or any mixture of $\mathrm{NH}_{4} \mathrm{NO}_{3}$ (s) with other dry salt compounds. An example is given in Sect. S1.1 in the Supplement.

\subsubsection{RH $\geq$ RHD - pure compound}

For the wet case, with RH above the compound RHD or mixed solution RHD (see below), the situation is more complicated. In contrast to the gas-solid partitioning described above, the gas-liquid equilibrium partitioning of, e.g. gaseous ammonia, $\mathrm{NH}_{3}(\mathrm{~g})$ and nitric acid, $\mathrm{HNO}_{3}(\mathrm{~g})$, is in equilibrium with aqueous ammonium nitrate, $\mathrm{NH}_{4} \mathrm{NO}_{3}(\mathrm{aq})$, when the vapour pressure product of the gases exceeds its temperature and humidity-dependent equilibrium dissociation constant, $K_{\mathrm{p}, \mathrm{AN}}(T, \mathrm{RH})$. The salt compound formed is - when equilibrium is reached - additionally dissociated into a cation $\mathrm{NH}_{4}{ }^{+}$(aq) and anion $\mathrm{NO}_{3}{ }^{-}$(aq) pair. 
1. Following SP2006 (their Sect. 10.4.3), Reaction (R1) expands to

$$
\begin{aligned}
& \mathrm{NH}_{3}(\mathrm{~g})+\mathrm{HNO}_{3}(\mathrm{~g}) \Longleftrightarrow \mathrm{NH}_{4}^{+}(\mathrm{aq})+\mathrm{NO}_{3}^{-}(\mathrm{aq}) \\
& \mathrm{EQ}:\left[\mathrm{NH}_{3}(\mathrm{~g})\right] \times\left[\mathrm{HNO}_{3}(\mathrm{~g})\right]=K_{\mathrm{p}, \mathrm{AN}}(T, \mathrm{RH})= \\
& \frac{\gamma_{\mathrm{AN}}^{2} \times \mu_{\mathrm{NH}_{4}^{+}(\mathrm{aq})} \times \mu_{\mathrm{NO}_{3}^{-}(\mathrm{aq})} .}{K_{\mathrm{AN}}} .
\end{aligned}
$$

For Reaction (R2) the equilibrium partitioning dissociation constant is now a function of $T$ and $\mathrm{RH}$. In the notation of SP2006 (see their Eq. 10.99), $K_{\mathrm{p}, \mathrm{AN}}(T, \mathrm{RH})$ is related to the temperature-dependent equilibrium constant $K_{\mathrm{AN}} . K_{\mathrm{AN}}\left[\mathrm{mol}^{2} \mathrm{~kg}^{-2} \mathrm{~atm}^{-2}\right]$ depends on the ion molalities $\left[\mathrm{mol} \mathrm{kg}^{-1}\left(\mathrm{H}_{2} \mathrm{O}\right)\right]$ of ammonium and nitrate, i.e. $\mu_{\mathrm{NH}_{4}^{+}(\mathrm{aq})}$ and $\mu_{\mathrm{NO}_{3}^{-}(\mathrm{aq})}$, and on the corresponding mean molal binary activity coefficient of aqueous ammonium nitrate, i.e. $\gamma_{\mathrm{AN}}^{2}$, squared because of the cationanion product. Solving Reaction (R2) requires iterations. To determine the aqueous phase concentration of all compounds that can exist in solution at given $T$ and $\mathrm{RH}$ requires knowledge of the total aerosol water mass (see below), which in turn depends on the solute concentrations and according to Reaction (R2) on activity coefficients. Thus, since $\gamma_{\text {AN }}$ is a function of the aqueous phase concentration, $K_{\mathrm{p}, \mathrm{AN}}(T, \mathrm{RH})$ has no analytical solution. According to the thermodynamic literature, the standard treatment is therefore quite comprehensive and requires complex thermodynamic codes.

2. Here we express the product $\left(\gamma_{\mathrm{AN}}^{2} \times \mu_{\mathrm{NH}_{4}^{+}(\mathrm{aq})} \times\right.$ $\mu_{\mathrm{NO}_{3}^{-} \text {(aq) }}$ ) of Reaction (R2) to be only a function of $\nu_{i}$ and $\mathrm{RH}$, which is motivated by M2012, since their $\mu_{\mathrm{S}}$ is only a function of $v_{i}$ and $\mathrm{RH}$. To be able to solve Reaction (R2) analytically, we parameterise $K_{\mathrm{p}, \mathrm{AN}}(T, \mathrm{RH})$ by introducing a solute-specific correction term for Reaction (R1), which only depends on RH:

$K_{\mathrm{p}}(T, \mathrm{RH})=K_{\mathrm{p}}(T) \times \operatorname{COEF}(\mathrm{RH})$.

At given $T$ and $\mathrm{RH}, K_{\mathrm{p}}(T, \mathrm{RH})$ is then a priori known, if $\mathrm{COEF}(\mathrm{RH})$ is independent of the solute concentration and associated water mass. This can be achieved either by fitting data (Metzger et al., 1999, 2002a; Hauglustaine et al., 2014), or expressing $\operatorname{COEF}(\mathrm{RH})$ in terms of the $v_{i}$ and the RH-dependent solute molality parameterisation of M2012, using their Eq. (5a). With a further comparison to Eq. (A11) of M2012, we can express the solute molality in terms of the solute mass fraction, $\chi_{\mathrm{s}}$, and define $\mathrm{COEF}(\mathrm{RH})$ for pure $\mathrm{NH}_{4} \mathrm{NO}_{3}(\mathrm{aq})$ solutions in terms of $\chi_{\mathrm{s}}(\mathrm{RH})$, i.e. for $\mathrm{RH} \geq \mathrm{RHD}$ :

$\operatorname{COEF}(\mathrm{RH}):=2 \times \chi_{\mathrm{s}}^{2}(\mathrm{RH})$,

where $\operatorname{COEF}(\mathrm{RH}):=1$ for $\mathrm{RH}<\mathrm{RHD}$. Equation (3) has been empirically derived to approximate the results obtained by ISORROPIA II (see Sect. 3$) \cdot \chi_{\mathrm{s}}(\mathrm{RH})$

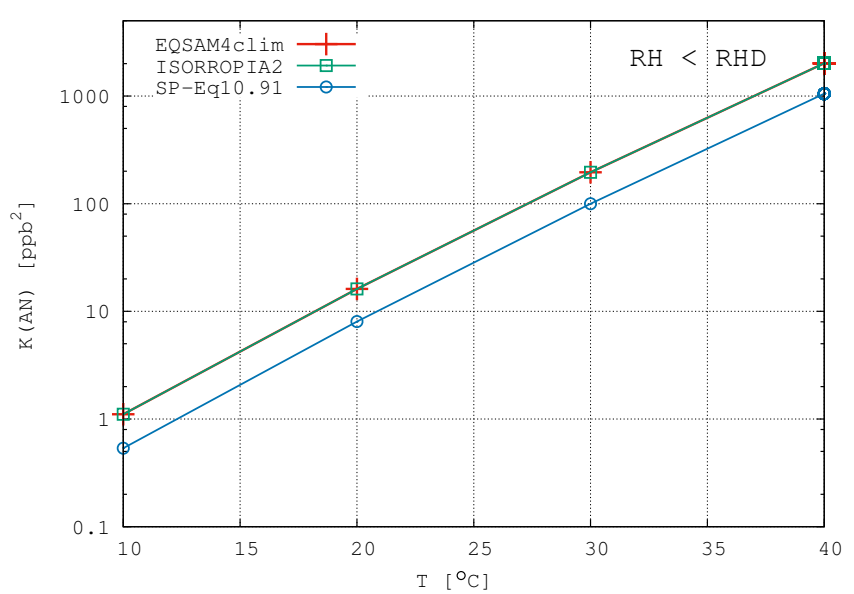

Figure 1. $\mathrm{NH}_{4} \mathrm{NO}_{3}$ equilibrium dissociation constant as function of $T$ at $\mathrm{RH}<\mathrm{RH}(\mathrm{AN})$. Red crosses show the values of EQSAM4clim, green squares refer to ISORROPIA II and the blue circles show Eq. (10.91) of Seinfeld and Pandis (2006); see their Fig. 10.19.

denotes the solute mass fraction, which requires in our mixed solution parameterisation framework only knowledge of RH and the solute-specific coefficient, $v_{i}$. In accord with the dry case (Reaction R1), aqueous solutions (Reaction R2) can now be analogously solved. Using Eqs. (2) and (3) to obtain $K_{\mathrm{p}, \mathrm{AN}}(T, \mathrm{RH})$ at a given $T$ and RH, the quadratic equation, which has an analytical solution for the dry case, can now also applied to pure $\mathrm{NH}_{4} \mathrm{NO}_{3}(\mathrm{aq})$ solutions. The direct solution of Reaction (R2) by using Eqs. (2) and (3) is exemplified in the Supplement.

The $T$-dependent equilibrium dissociation constant of $\mathrm{NH}_{4} \mathrm{NO}_{3}$, shown in Fig. 1, is also sensitive to changes in relative humidity and varies over orders of magnitude for typical ambient conditions. This is illustrated in Fig. 10.21 of SP2006, which we recommend to the reader for a detailed discussion. For comparison, Fig. 2 extends Fig. 1 showing the $K_{\mathrm{p}, \mathrm{AN}}(T, \mathrm{RH})$ values as a function of $\mathrm{RH}$ at $T=$ $298.15[\mathrm{~K}]$ for the EQSAM4clim and ISORROPIA II applications. The line points, which refer to pure $\mathrm{NH}_{4} \mathrm{NO}_{3}$ (aq) solutions, are relatively close for the EQSAM4clim and ISORROPIA II results, but both are (for RH $\leq$ RHD) roughly a factor 2 higher than the corresponding values of SP2006 (see Fig. 1); the constant $K_{\mathrm{p}, \mathrm{AN}}(T)$ of SP2006 is included for reference (at $T=298.15[\mathrm{~K}]$ ). Note that with Eq. (2) and the quadratic form of Eq. (3) we can analytically approximate the solution of $K_{\mathrm{p}, \mathrm{AN}}(T, \mathrm{RH})$ for $Y=1.0$ (Fig. 2). 


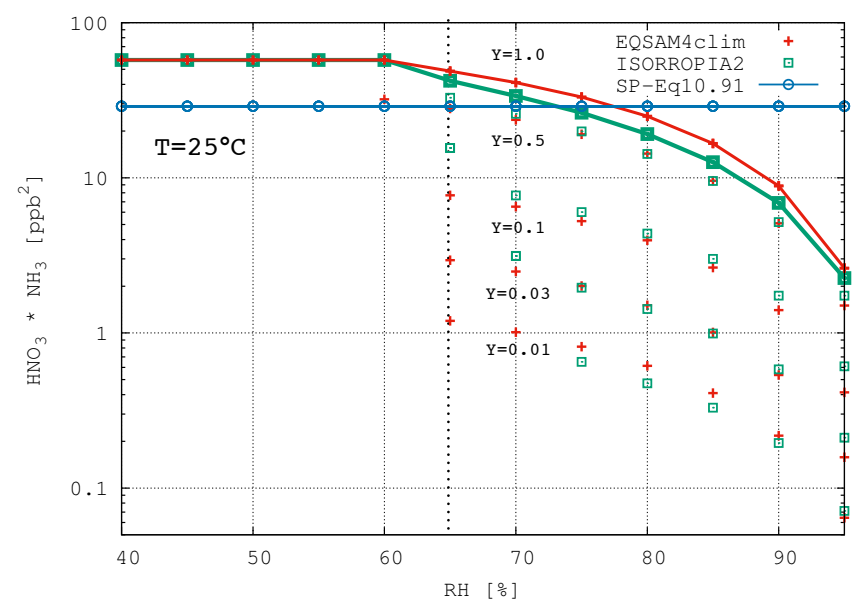

Figure 2. $\mathrm{NH}_{4} \mathrm{NO}_{3}$ equilibrium dissociation constant as function of RH (at $T=298.15[\mathrm{~K}]$ ) for various ionic strength factors $(Y)$ defined in Seinfeld and Pandis (2006); see their Fig. 10.21. Red crosses show the results of EQSAM4clim, green squares those of ISORROPIA II. The line points refer to pure ammonium nitrate $(Y=1)$. The vertical line at $\mathrm{RH}=65[\%]$ indicates the solid-liquid phase partitioning threshold for the mixed solution, shown in Seinfeld and Pandis (2006). The ordinate values refer to the product of $\left[\mathrm{NH}_{3}\right]_{(\mathrm{g}, \mathrm{AN})} \times\left[\mathrm{HNO}_{3}\right]_{(\mathrm{g}, \mathrm{AN})}$ that are obtained at end of the gas-liquid-solid $\mathrm{NH}_{4} \mathrm{NO}_{3}$ partitioning of ISORROPIA II, and by Eq. (9) for EQSAM4clim.

\subsubsection{RH $\geq$ RHD - mixed compound}

According to SP2006 (and references therein), Reaction (R2) needs to be extended for mixed aqueous solutions to include an ionic strength factor.

1. Following the notation of SP2006 (see their Eq. 10.100), the equilibrium concentration (either in [ppbv] or $\left[\mathrm{mol} \mathrm{m}-3\right.$ (air)]) of $\left[\mathrm{NH}_{4} \mathrm{NO}_{3}\right]$ in mixed aqueous solutions is controlled by the presence of ammonium sulfate, $\left[\left(\mathrm{NH}_{4}\right)_{2} \mathrm{SO}_{4}\right]$, and depends on a dimensionless ionic strength factor $Y$, which is defined by the ratio:

$$
Y:=\frac{\left[\mathrm{NH}_{4} \mathrm{NO}_{3}\right]}{\left[\mathrm{NH}_{4} \mathrm{NO}_{3}\right]+3 \times\left[\left(\mathrm{NH}_{4}\right)_{2} \mathrm{SO}_{4}\right]}
$$

To extend the calculation of the $T$ and RH-dependent equilibrium dissociation constant to the case of multicomponent aqueous solutions of $\mathrm{NH}_{4} \mathrm{NO}_{3}$, shown in Fig. 2, Eq. (4) needs to be considered such that $K_{\mathrm{p}, \mathrm{AN}}(T, \mathrm{RH})$ becomes $K_{\mathrm{p}, \mathrm{AN}}(T, \mathrm{RH}, Y)$.

2. To satisfy our key constraint (see Sect. 2) we avoid iterations in our mixed solution parameterisation. We therefore parameterise $K_{\mathrm{p}, \mathrm{AN}}(T, \mathrm{RH}, Y)$ by expanding Eq. (2) to be additionally a function of $Y$ (Eq. 4):

$$
K_{\mathrm{p}}(T, \mathrm{RH}, Y)=K_{\mathrm{p}}(T) \times \operatorname{COEF}(\mathrm{RH}, Y) .
$$

For Eq. (5), $\operatorname{COEF}(\mathrm{RH}, Y):=\operatorname{COEF}(\mathrm{RH}) \times Y^{0.8}$, where $\operatorname{COEF}(\mathrm{RH})$ is given by Eq. (3) and $Y$ by Eq. (4), for which we use the concentration given by the NRO (Sect. 2.3), i.e. $Y:=\frac{\left[\mathrm{NH}_{4} \mathrm{NO}_{3}\right]_{(\mathrm{nro}, \max )}}{\left.\left[\mathrm{NH}_{4} \mathrm{NO}_{3}\right]_{(\mathrm{nro}, \mathrm{max})}+3 \times\left[\mathrm{NH}_{4}\right)_{2} \mathrm{SO}_{4}\right]_{(\mathrm{nro})}}$. The $Y^{0.8}$ term has been empirically determined to approximate the results of ISORROPIA II by keeping the initial $\mathrm{NH}_{4} \mathrm{NO}_{3}$ and $\left(\mathrm{NH}_{4}\right)_{2} \mathrm{SO}_{4}$ concentrations constant. Since we do not use at this computation step any dissociation constant, we obtain the maximum concentrations (NRO, max) directly from the NRO (see Sect. 2.3). Equation (5) and the quadratic equation can be solved non-iteratively. The solution is detailed below (Sect. 2.5); examples are given in Sect. S1 in the Supplement.

Figure 2 shows that the results of EQSAM4clim and ISORROPIA II exhibit a similar dependency on $Y$ for $K_{\mathrm{p}, \mathrm{AN}}(T, \mathrm{RH}, Y)$, where the values decrease with decreasing $Y$ according to the results and the discussion of SP2006 (see their Fig. 10.21). $K_{\mathrm{p}, \mathrm{AN}}(T, \mathrm{RH}, Y)$ is given here by the product of the gaseous concentrations of ammonia, $\left[\mathrm{NH}_{3}\right]_{(\mathrm{g}, \mathrm{AN})}$, and nitric acid, $\left[\mathrm{HNO}_{3}\right]_{(\mathrm{g}, \mathrm{AN})}$, which are in equilibrium with either the solid $\left[\mathrm{NH}_{4} \mathrm{NO}_{3(\mathrm{~s})}\right]$ concentration, if $\mathrm{RH}<\mathrm{RHD}$, or in equilibrium with the aqueous $\left[\mathrm{NH}_{4} \mathrm{NO}_{3}(\mathrm{aq})\right]$ concentration when $\mathrm{RH} \geq \mathrm{RHD}$ in case of pure $\left[\mathrm{NH}_{4} \mathrm{NO}_{3}\right]$ (zero [ $\left.\left(\mathrm{NH}_{4}\right)_{2} \mathrm{SO}_{4}\right]$, where $\left.Y=1\right)$. Below the RHD, $K_{\mathrm{p}}(T, \mathrm{RH}, Y)$ reduces to $K_{\mathrm{p}}(T)$ as given by Eq. (1) in Reaction (R1). Differences, which occur mainly in the mixed deliquescence humidity range, are discussed below (Sect. 2.6).

\subsection{Solving $\mathrm{NH}_{4} \mathrm{NO}_{3} / \mathrm{NH}_{4} \mathrm{Cl}$-thermodynamic equilibrium - this work}

To analytically compute the equilibrium concentrations of the two semi-volatile compounds, $\mathrm{NH}_{4} \mathrm{NO}_{3}$ and $\mathrm{NH}_{4} \mathrm{Cl}$, for a given $\mathrm{RH}$ and $T$ with our mixed solution parameterisation, we first solve all neutralisation reactions at once for the domain by using the NRO (Table 3, Sect. 2.3) and the totals (gas + aerosol) of the cation and anion input concentrations. Thus, we obtain the free ammonium $\mathrm{TA}=\left[\mathrm{NH}_{4}^{+}\right]_{(\mathrm{nro}, \text { free })}$ and nitrate $\mathrm{TN}=\left[\mathrm{NO}_{3}^{-}\right]_{(\mathrm{nro}, \text { free })}$, after all higher ranked cation-anion paris are paired. To enable a non-iterative solution, we do not use at this computation step any dissociation constant, so that we directly obtain from $[\mathrm{TA}]$ and $[\mathrm{TN}]$ the corresponding maximum ammonium nitrate concentration $\left[\mathrm{NH}_{4} \mathrm{NO}_{3(\text { nro,max })}\right]=\operatorname{MIN}([\mathrm{TA}],[\mathrm{TN}])$, which is possible for $K_{\mathrm{p}}(T, \mathrm{RH}, Y)=1$ and the given input concentration, $T$ and RH. Analogously, we compute the maximum ammonium chloride concentration from the final free ammonium and free chloride, $[\mathrm{TC}]=[\mathrm{Cl}]_{(\text {nro,free) }}^{-}$, with $\left[\mathrm{NH}_{4} \mathrm{Cl}(\mathrm{nro}, \max )\right]=\mathrm{MIN}(\mathrm{TA}, \mathrm{TC})$.

With the initial (maximum) values of $\left[\mathrm{NH}_{4} \mathrm{NO}_{3 \text { (nro,max) }}\right]$ and $\left[\left(\mathrm{NH}_{4}\right)_{2} \mathrm{SO}_{4(\text { nro,max })}\right]$ we can solve Eq. (4). To obtain the final equilibrium concentrations, we compute the evaporative loss. For $\left[\mathrm{NH}_{4} \mathrm{NO}_{3 \text { (nro) }}\right]$, we compute the gaseous 


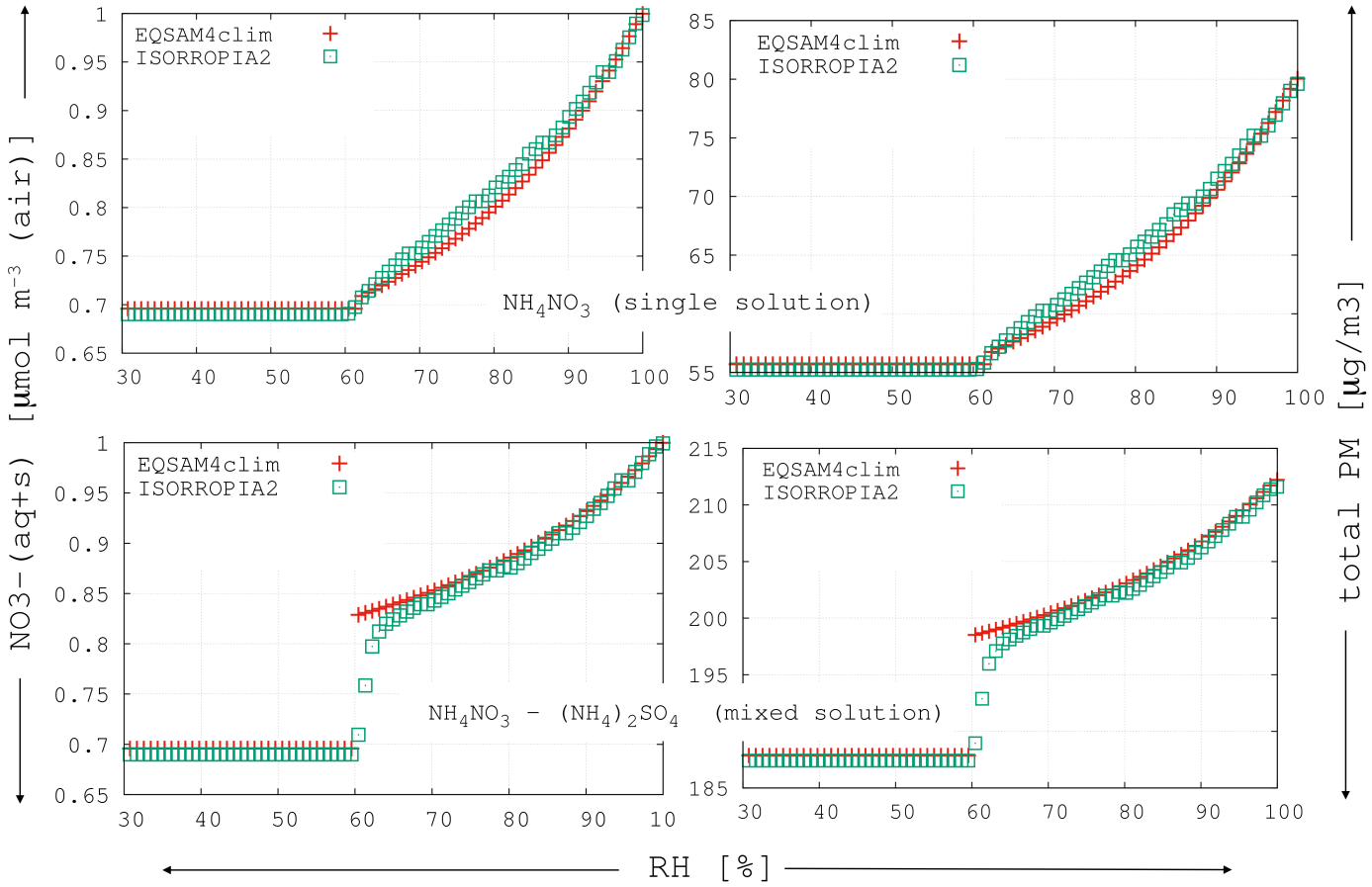

Figure 3. Results of EQSAM4clim (red crosses) and ISORROPIA II (green squares) for two idealised gas-liquid-solid partitioning examples: single solute (binary) solution of pure $\mathrm{NH}_{4} \mathrm{NO}_{3}$ (upper panels) and mixed solution of $\mathrm{NH}_{4} \mathrm{NO}_{3}$ and $\left(\mathrm{NH}_{4}\right)_{2} \mathrm{SO}_{4}$ with the concentration of each compound fixed to 1 [ $\mu \mathrm{molm}{ }^{-3}$ (air)] at $T=298.15 \mathrm{~K}$. The left panels show the $\mathrm{NH}_{4} \mathrm{NO}_{3}$ concentration in $\left[\mu \mathrm{mol} \mathrm{m}{ }^{-3}\right.$ (air)], the right panels show the corresponding particulate mass $\left[\mathrm{\mu g} \mathrm{m}^{-3}\right.$ (air)]. The mixed solution RHD described in Sect. 2.6 has been neglected for EQSAM4clim for this case, since this figure presents only an example for Sects. 2.4 and 2.5 (Sect. 2.6 is considered below).

ammonia, $\left[\mathrm{NH}_{3}\right]_{(\mathrm{g}, \mathrm{AN})}$, and nitric acid, $\left[\mathrm{HNO}_{3}\right]_{(\mathrm{g}, \mathrm{AN})}$ from $\left[\mathrm{NH}_{4} \mathrm{NO}_{3,(\mathrm{nro}, \max )}\right]$ :

$[\mathrm{TN}]=\left[\mathrm{NO}_{3}^{-}\right]_{(\mathrm{nro}, \text { free })}$,

$[\mathrm{TA}]=\left[\mathrm{NH}_{4}^{+}\right]_{(\text {nro,free })}$,

$[X]=\frac{1}{2} \times$

$(-([\mathrm{TA}]+[\mathrm{TN}])+$

$\left.\sqrt{([\mathrm{TA}]+[\mathrm{TN}])^{2}+4 \times K_{\mathrm{p}}(T, \mathrm{RH}, Y) /(\mathrm{RT})^{2}}\right)$,

where the variable $[X]$ is used to obtain

$$
\begin{aligned}
& {\left[\mathrm{NH}_{3}\right]_{(\mathrm{g}, \mathrm{AN})}=\left[\mathrm{HNO}_{3}\right]_{(\mathrm{g}, \mathrm{AN})}=} \\
& \operatorname{MIN}\left(\left[\mathrm{NH}_{4} \mathrm{NO}_{3}\right]_{(\mathrm{nro}, \mathrm{max})},[X]\right) .
\end{aligned}
$$

With Eq. (9) we compute the final gaseous concentrations of $\mathrm{HNO}_{3(\mathrm{~g})}$ and $\mathrm{NH}_{3(\mathrm{~g})}$ from

$\left[\mathrm{NH}_{3}\right]_{(\mathrm{g})}=[\mathrm{TA}]+\left[\mathrm{NH}_{3}\right]_{(\mathrm{g}, \mathrm{AN})}$,

$\left[\mathrm{HNO}_{3}\right]_{(\mathrm{g})}=[\mathrm{TN}]+\left[\mathrm{HNO}_{3}\right]_{(\mathrm{g}, \mathrm{AN})}$,

and the final ammonium nitrate equilibrium concentration from

$\left[\mathrm{NH}_{4} \mathrm{NO}_{3}\right]_{(\mathrm{nro})}=\left[\mathrm{NH}_{4} \mathrm{NO}_{3}\right]_{(\mathrm{nro}, \max )}-\left[\mathrm{HNO}_{3}\right]_{(\mathrm{g}, \mathrm{AN})}$.
One can now solve with Eqs. (6)-(12) the quadratic equation for the dry, pure or mixed solution cases. But, in contrast to Seinfeld and Pandis (1998) (see their Eq. 9.103), we compute with Eq. (8) the evaporative losses of gaseous concentrations at equilibrium.

Figure 3 shows a comparison of idealised box model calculations of EQSAM4clim (see Appendix B) and ISORROPIA II (more comprehensive calculations are shown in Sect. 3). The upper panels show the gas-liquid-solid partitioning concentration of $\mathrm{NH}_{4} \mathrm{NO}_{3}$ for a binary solution with a fixed concentration of $1\left[\mu \mathrm{mol} \mathrm{m}{ }^{-3}\right.$ (air)] of pure $\mathrm{NH}_{4} \mathrm{NO}_{3}$, while the lower panels show the same for a mixed solution with each $1\left[\mu \mathrm{molm}{ }^{-3}\right.$ (air)] of $\mathrm{NH}_{4} \mathrm{NO}_{3}$ and $\left(\mathrm{NH}_{4}\right)_{2} \mathrm{SO}_{4}$ (both at $T=298.15 \mathrm{~K}$ ). The left panels show $\mathrm{NH}_{4} \mathrm{NO}_{3}$, the right the corresponding total mass loading. To solve the gas-solid and gas-liquid partitioning we have used the $v_{i}$ based framework (Sect. 2) for EQSAM4clim, and for ISORROPIA II the option to iteratively calculate activity coefficients. A detailed calculation for this example is given in the Supplement (Sect. S1). Despite fundamental differences in both approaches, the comparison of these results is satisfactory for mixed solute concentration from which the aerosol water mass is derived in a subsequent calculation step - for EQSAM4clim without iterations. 


\subsection{Mixed solution RHD}

To calculate the liquid-solid partitioning, we follow (Fountoukis and Nenes, 2007) and consider a mutual deliquescence RH range. In our framework, it depends on a minimum and maximum threshold: RHDMIN and RHDMAX, which are defined below. When the RH is below RHDMIN the aerosol is considered to be dry, while for RH above RHDMAX the aerosol is considered wet with all ionic compounds dissolved. In between a mixture can exist, with some compounds dissolved while other compounds are precipitated from the solution.

For mixed solutions (two or more compounds and water), only the amount that exists for RH $>$ RHDMIN is considered in solution and allowed to contribute to the mixed solution water uptake. Otherwise, the compounds are considered to be instantaneously solid and precipitated from the solution. For all non-precipitated compounds, a weighted solute concentration is computed from which subsequently all partial water masses are obtained. The sum of all partial water masses yields the total water for the given aerosol composition, size, $T$ and RH (see Sect. 2.7).

However, comparing the water uptake calculation of EQSAM4clim with reference calculations of, e.g. ISORROPIA II and E-AIM is somewhat precarious. The reason is that for mixed solutions the calculated water mass mainly depends on the threshold at which the mixture is considered to take up water. The assumptions made to define the mixed solution RHD, or the mutual deliquescence RH range, are generally a major source of uncertainty in modelling the aerosol associated water uptake. First we discuss the procedure of Fountoukis and Nenes (2007), and then we describe our single parameter approach.

1. For ISORROPIA II, if the RH is within a mutual deliquescence RH range, the so-called MDRH region, the solution is assumed to be the sum of two weighted solutions; a "dry solution" (considering a pure dry case) and a "saturated liquid" solution (considering a pure liquid case). Then a numerical solution needs to be found based on a weighting factor (WF) for the dry and liquid solution that could be present in the given sub-domain (solute composition). The weighting factors are obtained from (RHD - RH)/(RHD - MDRH) using prescribed MDRH values, which have been measured and tabulated for certain mixtures of salt solutes (see Fountoukis and Nenes, 2007). When the RH is below the MDRH, only a solid phase is possible. Otherwise a liquid and solid phase may coexist (with $\mathrm{MDRH}<\mathrm{RH}<\mathrm{RHD}$ ). For the latter case the aqueous phase concentrations are determined by WF. The summation over all partial water masses then yields the total aerosol water mass. But the gas-liquid-solid partitioning is reiterated until the solution converges and the concentrations do not change further (equilibrate). For details see Fountoukis and Nenes (2007).

2. Here we follow the idea of a weighted mixed solution approach of ISORROPIA II, but we approximately solve the liquid-solid partitioning by computing the weighting factor non-iteratively. We compute the liquid-solid partitioning after solving the NRO (Sect. 2.3) and the gas-liquid partitioning (Sect. 2.4). For each salt compound $(j)$ we analytically obtain the solid concentration $n_{j(\mathrm{~s})}$ from its aqueous $n_{j(\mathrm{nro})}$ concentration (determined in the previous computation steps). Analogously to Fountoukis and Nenes (2007), we use a mixed solution weighting factor, $\mathrm{WF}_{j \text {, mix }}$ :

$n_{j(\mathrm{~s})}=n_{j(\mathrm{nro})} \times \mathrm{WF}_{j, \text { mix }}$,

with

$n_{j(\mathrm{aq})}=n_{j(\mathrm{nro})}-n_{j(\mathrm{~s})}$,

where $n_{j \text { (nro) }}$ denotes an aqueous concentration of, e.g. $\left[\mathrm{NH}_{4} \mathrm{NO}_{3}\right]_{(\mathrm{nro})}$ from Eq. (12).

$\mathrm{WF}_{j \text {,mix }}$ is defined for each compound (the $j$ th salt solute in Table 3) by

$\mathrm{WF}_{j, \text { mix }}:=$

$$
\left(\text { RHDMAX }_{j}-\mathrm{RH}\right) /\left(\mathrm{RHDMAX}_{j}-\mathrm{RHDMIN}\right)
$$

always with a positive sign: RHDMIN $<$ RHDMAX $_{j}$ and $\mathrm{RH}<\mathrm{RHDMAX}_{j}$. RHDMIN and $\mathrm{RHDMAX}_{j}$ are defined below. For $\mathrm{RH} \geq \mathrm{RHDMAX}_{j}, \mathrm{WF}_{j, \text { mix }}=0$; $\mathrm{RH} \leq \mathrm{RHDMIN}, \mathrm{WF}_{j, \mathrm{mix}}=1$. Note that we use a different notation of RHDMIN and RHDMAX $_{j}$ (instead of the MDRH and RHD used by Fountoukis and Nenes, 2007) to indicate that we are using different values and underlying mixed solution calculations, which do not necessarily have to yield the same results despite our constraint that the overall liquid-solid partitioning aims to be comparable.

To solve the liquid-solid partitioning analytically, i.e. without iteration, we modify the approach of Fountoukis and Nenes (2007). Each binary concentration $n_{j(\mathrm{nro})}$ is weighted by the total solute concentration, $n_{\mathrm{s}, \mathrm{sum}(\mathrm{nro})}=\sum_{j=1, N_{\max }} n_{j(\mathrm{nro})}$ with all concentration units in $\left[\mathrm{mol} \mathrm{m}^{-3}\right.$ (air)]. But in our framework, $n_{\mathrm{s}, \mathrm{sum} \text { (nro) }}$ is directly obtained from the sum of all single solute concentrations that are formed by solving the neutralisation reaction order (Sect. 2.3). In case a semivolatile compound has been initially neutralised, e.g. $\left[\mathrm{NH}_{4} \mathrm{NO}_{3}\right]_{(\mathrm{nro}, \max )}$, we additionally solve Eqs. (6)-(12) to obtain $n_{j(\text { nro })}=\left[\mathrm{NH}_{4} \mathrm{NO}_{3}\right]_{(\text {nro) }}$ (Sect. 2.4), before we obtain a solute-specific weighting factor, $\mathrm{WF}_{j}$, from:

$\mathrm{WF}_{j}:=\frac{n_{j(\mathrm{nro})}}{n_{\mathrm{s}, \mathrm{sum}(\mathrm{nro})}}=\frac{n_{j(\mathrm{nro})}}{\sum_{j=1, N_{\max }} n_{j(\mathrm{nro})}}$. 


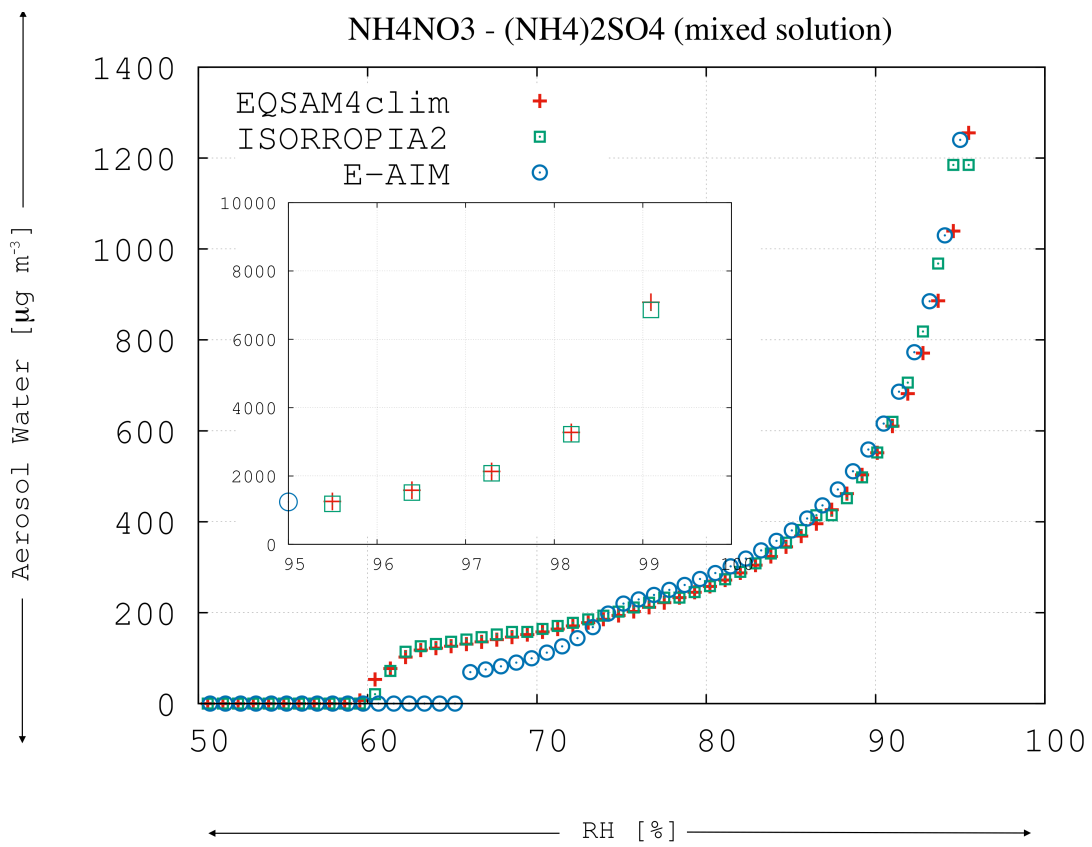

Figure 4. Results of EQSAM4clim (red crosses) and ISORROPIA II (green squares) for the total aerosol water mass $m_{\mathrm{w}, \mathrm{mix}}$ [kg m ${ }^{-3}$ (air)] obtained by Eq. (22) for the mixed solution of $\mathrm{NH}_{4} \mathrm{NO}_{3}$ and $\left(\mathrm{NH}_{4}\right)_{2} \mathrm{SO}_{4}$ shown in Fig. 3 (lower panels). The results are shown for $\mathrm{RH}=50-$ 97 [\%] (large panels) and for the $\mathrm{RH}=95-99.5$ [\%] (small panel). The results of E-AIM (web version) (blue circles) are included for comparison. The mixed solution RHD has been obtained for EQSAM4clim from Eqs. (13)-(22) and are based on measured MDRH values for ISORROPIA II. The mutual deliquescence range of EQSAM4clim and ISORROPIA II (described in Sect. 2.6) differs from those of E-AIM (web version: http://www.aim.env.uea.ac.uk/aim/aim.php. This figure is extended by Fig. S3.

The maximum value of $N_{\max }$ is limited by the domaindependent NRO (see Table 3). It refers to aqueous solutes at this stage. The liquid-solid partitioning is computed below.

The concentration-weighted maximum $\mathrm{RHD}_{j}$ (upper threshold), which normally needs to be computed iteratively for each compound, is here directly obtained using $\mathrm{WF}_{j}$ :

$$
\begin{aligned}
& \operatorname{RHDMAX}_{j}:=\mathrm{RHDMIN} \times \mathrm{WF}_{j}^{0.25}+\mathrm{RHD}_{j} \\
& \times\left(1-\mathrm{WF}_{j}^{0.25}\right) .
\end{aligned}
$$

In case of mixed solutions, Eq. (17) is used to obtain the upper RH threshold, otherwise the compound's $\mathrm{RHD}_{j}$ given in Table 1 are used, while RHDMIN is computed

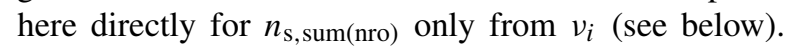
$\mathrm{WF}_{j}$ is introduced here with an exponent (empirically derived) to parameterise the results of ISORROPIA II, which uses iterations to solve the liquid-solid partitioning using MDRH measurements as the lower RHthreshold in Eq. (17).

To adhere to our key-constraints (Sect. 2, i.e. to minimise the dependency on the required thermodynamic data), we compute the RHDMIN from Eq. (5b) of M2012 (or Eq. A6 of the Appendix), by using the mixed solution values for $\mu_{\mathrm{s}}$ and $v_{i}$ that correspond to $n_{\mathrm{s}, \mathrm{sum} \text { (nro) }}$ (Eq. 16). Assuming $K_{\mathrm{e}}=1, A=1$ and $B=0$, the single RHDMIN value can be obtained from

$$
\begin{aligned}
& \text { RHDMIN }:= \\
& \left(1+\mu_{\mathrm{s}}^{\mathrm{o}} \times M_{\mathrm{w}} \times v_{i, \text { mix }} \times\left(\frac{1}{\mu_{\mathrm{s}}^{\mathrm{o}}} \times \mu_{\mathrm{s}, \mathrm{sat}, \text { mix }}\right)^{v_{i, \text { mix }}}\right)^{-1} .
\end{aligned}
$$

$\mu_{\mathrm{s}, \text { sat,mix }}$ is the saturation solute molality and $v_{i, \text { mix }}$ the solute-specific constant of the mixed solution. $\mu_{\mathrm{s} \text {,sat,mix }}$ and $v_{i, \text { mix }}$ are introduced here. $\mu_{\mathrm{s}}^{\mathrm{o}}=1\left[\mathrm{~mol} \mathrm{~kg}^{-1}\right]$ is the reference molality to match units. $M_{\mathrm{w}}\left[\mathrm{kg} \mathrm{mol}^{-1}\right]$ is the molar mass of water.

Due to a lack of experimental data, we approximate $\mu_{\mathrm{s}, \text { sat,mix }}$ from the summation over all single solute molalities, $\mu_{\mathrm{s} \text {, sat,single }}\left[\mathrm{mol} \mathrm{kg}^{-1}\right.$ ], using the relation to the mass fraction solubility (see, e.g., Eq. A11 of M2012). We therefore obtain $\mu_{\mathrm{s} \text {, sat,mix }}$ from

$$
\begin{aligned}
& \mu_{\mathrm{s}, \text { sat,mix }}:= \\
& \sum_{j=1, N_{\max }}\left[\frac{1}{M_{j(\text { single })} \times\left(100 / W_{j(\text { single })}-1\right)}\right] .
\end{aligned}
$$

$M_{j \text { (single) }}\left[\mathrm{kg} \mathrm{mol}^{-1}\right]$ is the single solute molar mass,

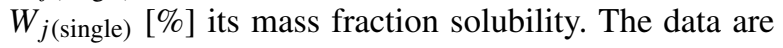


given in Table 1 for all compounds considered in this work.

With the mixed solution molality, $\mu_{\mathrm{s}, \mathrm{sat} \text { mix }}$, we can directly compute the mixed solution solubility, $w_{\mathrm{s} \text {, mix }}$, if we use as the corresponding total molar mass the sum of the molar masses over all $\left(N_{\max }\right)$ compounds that can dissolve in the mixed solution, i.e. $M_{\mathrm{s}, \operatorname{mix}}=$ $\sum_{j=1, N_{\max }} M_{j \text { (single) }}$ (same compounds and $N_{\max }$ as in Eq. 16):

$w_{\mathrm{s}, \text { mix }}:=\frac{1}{\left(\mu_{\mathrm{s}, \mathrm{sat}, \text { mix }} \times M_{\mathrm{s}, \text { mix }}\right)^{-1}+1}$,

where $0.1<w_{\mathrm{s} \text {,mix }}<1$. Finally, we can obtain with Eq. (20) the solute-specific constant that corresponds to the mixed solution, $v_{i, \mathrm{mix}}$, using an empirical equation that approximates $v_{i, \text { mix }}$ from the corresponding mixed solution solubility $w_{\mathrm{s}, \operatorname{mix}}$ :

$v_{i, \text { mix }}:=\left(0.25 \times \ln \left(w_{\mathrm{s}, \text { mix }}\right)+1\right)^{-1}$.

Thus, with Eq. (19) we solve Eq. (20) and with Eq. (20) we solve Eq. (21). With Eqs. (21) and (19) we solve Eq. (18) to obtain RHDMIN. Furthermore, with Eq. (16)

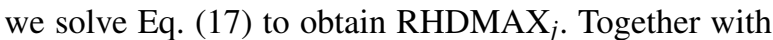
RHDMIN we solve Eq. (15) to obtain $\mathrm{WF}_{j, \text { mix }} . \mathrm{WF}_{j, \text { mix }}$ is then used to compute the liquid-solid partitioning from Eqs. (13)-(14) after solving the NRO (Sect. 2.3) and the gas-liquid partitioning (Sect. 2.4), in case of semi-volatile compounds. Finally, the aerosol water uptake is computed for each salt compound that exists in the aqueous phase at the given $T$ and $\mathrm{RH}$ from $n_{j(\mathrm{aq})}$ (Eq. 14). See Figure S2.2 in the Supplement for a flow chart of the calculation.

\subsection{Aerosol water uptake}

To calculate the mixed solution aerosol water uptake, the standard procedure employs the widely used ZSR-mixing rule (see, e.g., SP2006, Eq. 10.98). Assuming that solute concentrations are in equilibrium with the ambient air, the total aerosol water mass, $m_{\mathrm{w}(\text { mix })}\left[\mathrm{kg} \mathrm{m}^{-3}\right.$ (air)], can be directly obtained from the sum of all pure compound partial aerosol water masses in the case of a mixed solution ( $N$ compounds dissolved):

$m_{\mathrm{w}, \text { mix }}=\sum_{j=1, N} m_{\mathrm{w}, j}=\sum_{j=1, N} \frac{n_{j(\mathrm{aq})}}{\mu_{j(\mathrm{aq})}}$.

Here we follow the standard procedure, while the liquidsolid partitioning and the $N$ compounds in the aqueous phase are solved non-iteratively with Sect. 2.6. $N$ can differ from $N_{\max }$ considered in Eq. (16), because certain salt solutes may precipitate from the mixed solution during the

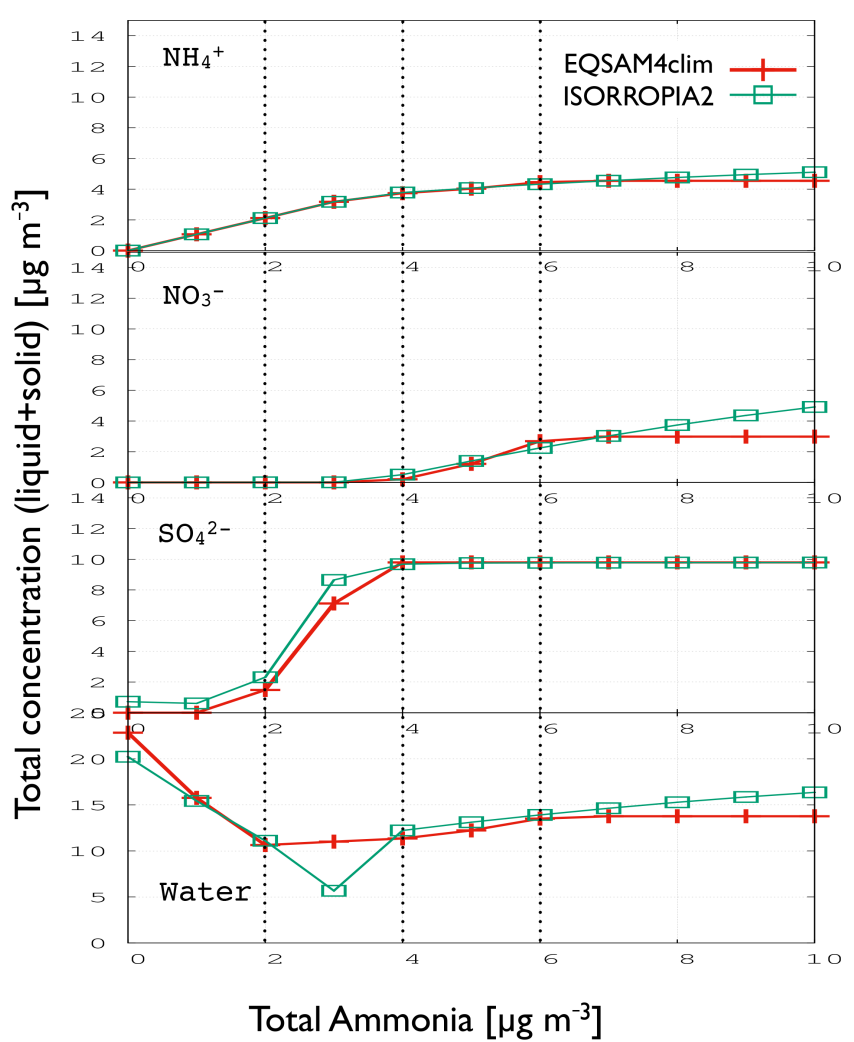

Figure 5. Mixed solution composition of $\mathrm{NH}_{4} \mathrm{NO}_{3}$ and $\left(\mathrm{NH}_{4}\right)_{2} \mathrm{SO}_{4}$ as a function of total ammonia at $T=298.15[\mathrm{~K}]$ and $\mathrm{RH}=70[\%]$, as defined in Seinfeld and Pandis (2006) for their Fig. 10.23. EQSAM4clim (red crosses) and ISORROPIA II (green squares) for $[\mathrm{TS}]=[\mathrm{TN}]=10\left[\mu \mathrm{g} \mathrm{m}^{-3}\right.$ (air) $]$. Note that at zero ammonia, $\mathrm{H}_{2} \mathrm{SO}_{4}$ is at a maximum; shown in Fig. $\mathrm{S} 4$

liquid-solid partitioning so that $N \leq N_{\max }$. With increasing RH (from RHDMIN up to $\mathrm{RHDMAX}_{j}$ ), an increasing number of compounds are considered for the water uptake calculations by Eq. (22). The partial aerosol water masses, $m_{\mathrm{w}, j}$, which are associated with each binary solution (one compound and water), $n_{j(\text { aq) }}\left[\mathrm{mol} \mathrm{m}^{-3}\right.$ (air)], can be directly obtained from tabulated single solute molalities, $\mu_{j(\mathrm{aq})}\left[\mathrm{mol}\right.$ (solute) $\left.\mathrm{kg}^{-1}\left(\mathrm{H}_{2} \mathrm{O}\right)\right]$ (see Appendix A1), or parameterised based on Eq. (5a) of M2012 (Appendix A2, Eq. A3).

In case the RH is below the $T$-dependent RHD or the RHDMIN, we assume the compound to be dry and the partial aerosol water mass to be zero. Using the $\mathrm{RH}$-dependent $\mu_{j \text { (aq) }}$ parameterisation of M2012 (their Eq. 5a), we can solve Eq. (22) without iterations.

Our mixed solution framework is independent of the total aerosol water mass because

1. $n_{j(\mathrm{aq})}$ is independent of $m_{\mathrm{w}, \mathrm{mix}}$, since it is directly given by our NRO (Sect. 2.3); 


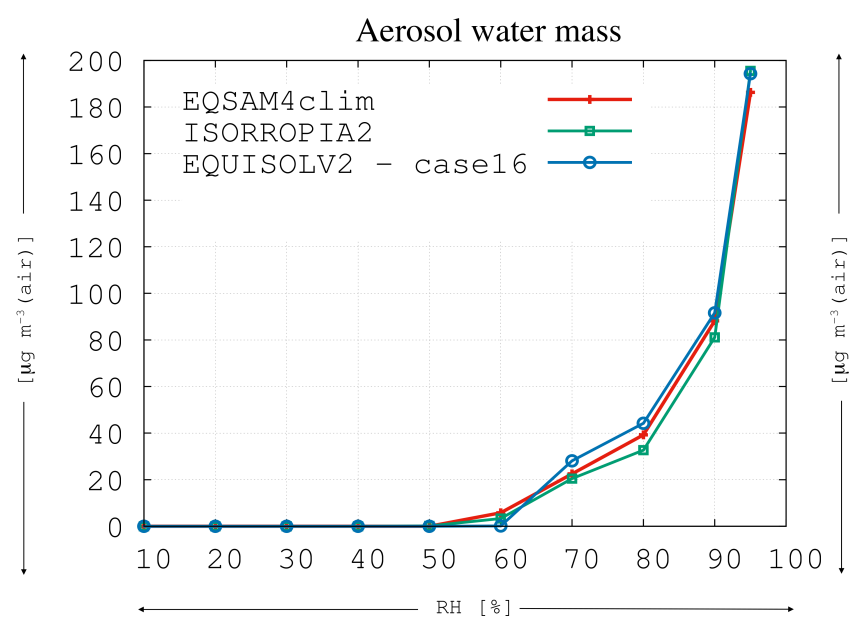

Figure 6. EQUISOLV II comparison - case 16. Bulk aerosol water mass as a function of RH for different sulfate molar ratios, fixed for the entire $\mathrm{RH}$ range (at constant $T=298.15 \mathrm{~K}$ ). The dry concentration ratios of sulfate are $\frac{\mathrm{tNH}_{4}}{\mathrm{tSO}_{4}}=2.0, \frac{\mathrm{tNO}_{3}}{\mathrm{tSO}_{4}}=1.0, \frac{\mathrm{tNaCl}}{\mathrm{tSO}_{4}}=0.5$, $\frac{\mathrm{tK}}{\mathrm{tSO}_{4}}=0.04, \frac{\mathrm{tCa}}{\mathrm{tSO}_{4}}=0.02, \frac{\mathrm{tMg}}{\mathrm{tSO}_{4}}=0.01$ and corresponds to domain 1 of Table 2. This figure is extended to various (20 cases) sulfate molar ratios that are shown in Fig. S5 and correspond to Table 3 of $\mathrm{Xu}$ et al. (2009).

2. $K_{\mathrm{p}, \mathrm{AN}}(T, \mathrm{RH}, Y)$ is independent of $m_{\mathrm{w}, \text { mix }}$, because of our $\chi_{\mathrm{s}}(\mathrm{RH})$-based parameterisations of semi-volatile compounds, i.e. Eqs. (2)-(5) (Sect. 2.4)

3. $\chi_{\mathrm{s}}(\mathrm{RH})$ is independent of $m_{\mathrm{w}, \mathrm{mix}}$, since it is directly given by $\mu_{j(\mathrm{aq})}(\mathrm{RH})$ (depending also only on $v_{i}$, and RH due to the relation Eq. A11 of M2012);

4. $\mu_{j(\mathrm{aq})}$ is independent of $m_{\mathrm{w}, \mathrm{mix}}$, since it only depends on $v_{i}$, and RH ( $\mu_{j(\mathrm{aq})}$ is based on Eq. 5a of M2012 and included with $\chi_{\mathrm{s}}$ in Appendix A);

5. Mixed solution RHDMIN is independent of $m_{\mathrm{w}, \mathrm{mix}}$, because of our mixed solution weighting factor, $\mathrm{WF}_{\mathrm{mix}}$, parameterisations, which also only depend on $v_{i}$, and RH.

6. $m_{\mathrm{w}, j}$ is independent of $m_{\mathrm{w}, \mathrm{mix}}$, because of the independence of points $1-5$.

Finally, Eq. (22) is solved for diagnostic output only, since $m_{\mathrm{w}, \mathrm{mix}}$ does not need to be recalculated. Different from ISORROPIA II $m_{\mathrm{w}, j}$ and $m_{\mathrm{w}, \text { mix }}$ are not central in our gasliquid-solid partitioning computations because of the $v_{i}$ concept, which requires that the thermodynamic key-properties, $\mu_{j \text { (aq) }}$ and $\chi_{\mathrm{s}}$, only depend on RH and $v_{i}$. Note that Eq. (22) can be equally used for so-called metastable aerosols, for which the formation of solid salts is generally not considered.

\section{Application}

We apply our parameterisation using EQSAM4clim. EQSAM4clim is entirely based on the mixed solution framework described in Sect. 2, which builds on the $v_{i}$ approach of M2012. The underlying single solute parameterisation of solute molality, $\mu_{\mathrm{s}}$, and the relation to the solute mass fraction, $\chi_{\mathrm{s}}$, are summarised in Appendix A. The Appendix also includes a short description of EQSAM4clim (Sect. B), while the computational algorithm of EQSAM4clim is detailed in the Supplement (Sect. S2).

To evaluate EQSAM4clim we compare the single solute and mixed solution aerosol water uptake, as well as various other aerosol properties, against different reference models using box and global modelling calculations at various levels of complexity (see Table A1 for abbreviations):

1. fixed solute concentrations ( 9 cases): ISORROPIA II and E-AIM

(see also Sect. S3.1 in the Supplement);

2. variable ammonia concentration: ISORROPIA II and SP2006

(see also Sect. S3.2 in the Supplement);

3. variable solute concentrations (20 cases): ISORROPIA II and EQUISOLV II

(see also Sect. S3.3 in the Supplement);

4. field observations (MINOS campaign, 184 cases): ISORROPIA II

(see also Sect. S3.4 in the Supplement);

5. EMAC chemistry-climate model (year 2005): ISORROPIA II.

Selected results of each application case (1-5) are shown below, while the complete set of results are shown in the Supplement (Sect. S3). Throughout this work, all EQSAM4clim results will be primarily evaluated with respect to its ability to accurately simulate the water uptake of atmospheric aerosols, as this is a key process in climate modelling with our EMAC chemistry-climate model.

\subsection{Fixed solute concentrations ( 9 cases): ISORROPIA II and E-AIM}

Figure 4 shows the total aerosol water mass, $m_{\mathrm{w}, \text { mix }}$ $\left[\mathrm{kg} \mathrm{m}^{-3}\right.$ (air)] obtained by Eq. (22) for EQSAM4clim in comparison to the results of ISORROPIA II and E-AIM for the mixed solution case of $\mathrm{NH}_{4} \mathrm{NO}_{3}$ and $\left(\mathrm{NH}_{4}\right)_{2} \mathrm{SO}_{4}$ shown in Fig. 3 (lower panels). The results are based on the full gas-liquid-solid partitioning for EQSAM4clim in Sect. 2. This first example considers the simplest calculation case: dry compound concentration fixed to $1\left[\mu \mathrm{mol} \mathrm{m}^{-3}\right.$ (air)]. Figures 4 and S3 in the Supplement (see Supplement, Sect. 3.1) 


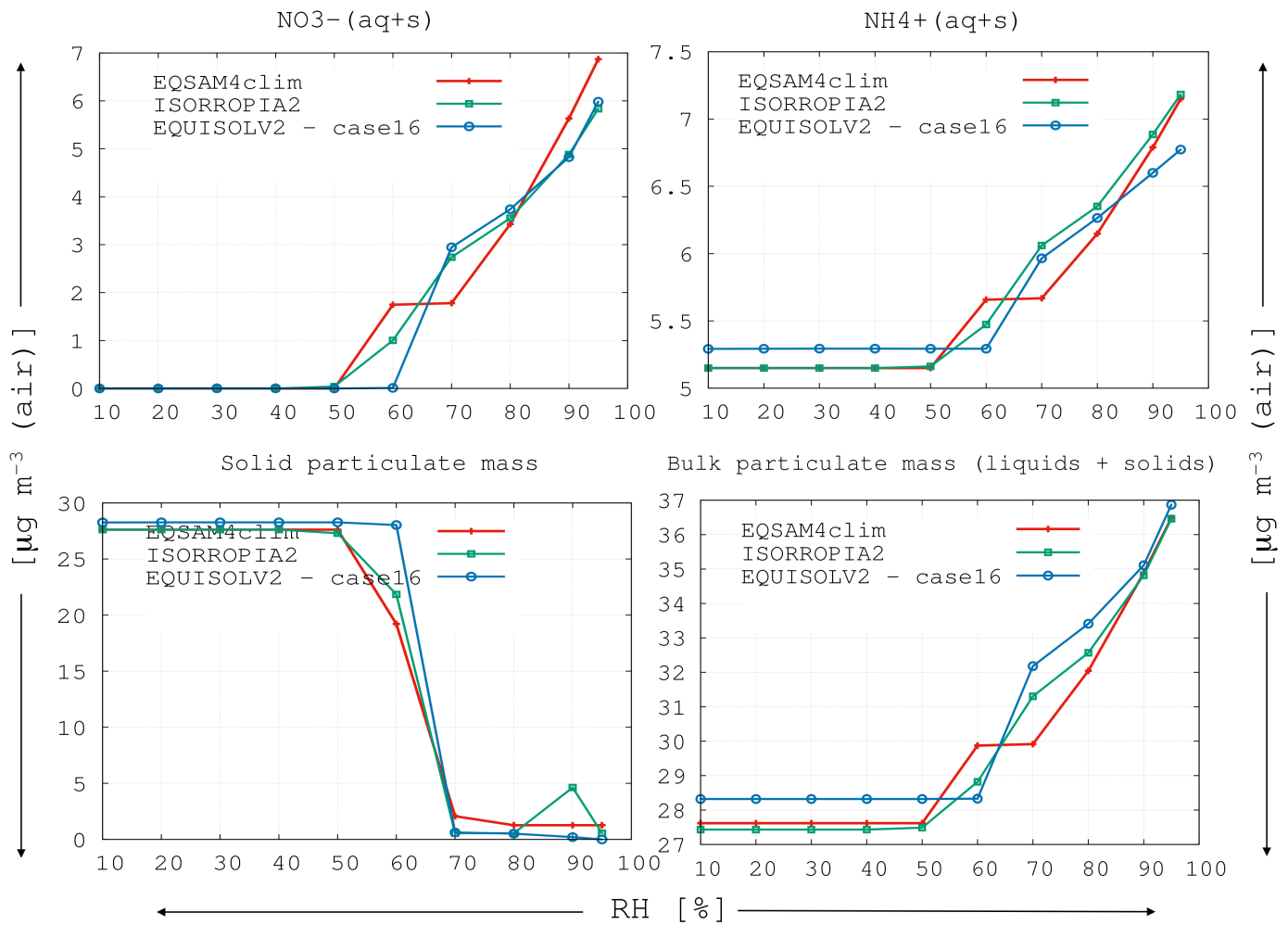

Figure 7. EQUISOLV II comparison - case 16. Bulk aerosol nitrate (ul), ammonium (ur), total solid PM (ll), liquid + solid PM (lr) as a function of RH for the sulfate molar ratios shown in Fig. 6. This figure is extended by Figs. S6 and S7.

show that the relatively largest differences occur for all cases in the (mutual) deliquescence range, while the general water uptake above this range is very similar for all three equilibrium models, despite the fundamental differences in the underlying approaches of the thermodynamic models.

\subsection{Variable $\mathrm{NH}_{3}$ concentration: ISORROPIA II and SP2006}

To further evaluate the aerosol water uptake calculations of EQSAM4clim for variable concentrations, we first compare the mixed solution composition of $\mathrm{NH}_{4} \mathrm{NO}_{3}$ and $\left(\mathrm{NH}_{4}\right)_{2} \mathrm{SO}_{4}$ (at $T=298.15 \mathrm{~K}$ ) as a function of total ammonia $\left(\mathrm{NH}_{3}+\mathrm{NH}_{4}^{+}\right)$, following SP2006; see their Fig. 10.23. Figure 5 shows the corresponding results in $\left[\mu \mathrm{g} \mathrm{m}^{-3}\right.$ (air)] of EQSAM4clim and ISORROPIA II - (from top to bottom) for ammonium, nitrate, sulfate and aerosol water, with bi-sulfate, sulfuric acid shown in the Supplement (Fig. S4). Overall, the results of EQSAM4clim and ISORROPIA II are close to those of Fig. 10.23 of SP2006. Minor differences in ammonium, nitrate and water occur at ammonia concentrations above $6\left[\mathrm{\mu g} \mathrm{m}^{-3}\right.$ (air)], since the gaseous uptake of $\mathrm{NH}_{3}$ and $\mathrm{HNO}_{3}$ on saturated solutions is not considered for EQSAM4clim; see Supplement (Sect. S2). The EQSAM4clim results are for ammonia concentrations below $6\left[\mu \mathrm{g} \mathrm{m}^{-3}\right.$ (air)] somewhat closer to those of SP2006 (see their Fig. 10.23), while the opposite is true for higher ammonia concentrations.

\subsection{Variable solute concentrations ( 20 cases): ISORROPIA II and EQUISOLV II}

To scrutinise the differences between EQSAM4clim and ISORROPIA II, we further evaluate 20 variable mixed solution cases, following the comparison presented in $\mathrm{Xu}$ et al. (2009), using the corresponding sulfate molar ratios of their Table 3. Figures 6 and 7 show the modelling results for the following RHs: $10,20,30,40,50,60,70,80,90,95$ [\%] in comparison to EQUISOLV II for case 16, which corresponds to domain D1 of Tables 2 and 3. The remaining cases are shown in Figs. S5-S7 in the Supplement. The aerosol composition is calculated from the full gas-liquid-solid equilibrium partitioning with the assumption that the aerosol lies on the deliquescence branch. Again, this comparison indicates that the relatively largest differences in the aerosol water mass calculations occur in the mutual deliquescence humidity range, while the general water uptake above this range is rather similar for all three equilibrium models (Fig. 6). This finding is also supported by the solid and total PM and confirmed by the total aerosol ammonium and nitrate comparison (Fig. 7). For all cases, the results of EQSAM4clim are 
Table 5. MINOS aerosol statistics (see Figs. 8, 9 of Sect. 3.4; Appendix C for the evaluation metrics): EQSAM4clim (EQ4c) and ISORROPIA II (ISO2) versus MINOS observations (August 2001).

\begin{tabular}{|c|c|c|c|c|c|c|c|c|}
\hline & \multicolumn{8}{|c|}{ Aerosol fine mode } \\
\hline & \multicolumn{2}{|c|}{$\mathrm{HNO}_{3}$} & \multicolumn{2}{|c|}{$\mathrm{NH}_{3}$} & \multicolumn{2}{|c|}{$\mathrm{HCl}$} & \multicolumn{2}{|c|}{ PM } \\
\hline & EQ4c & $\mathrm{ISO} 2$ & EQ4c & ISO2 & EQ4c & $\mathrm{ISO} 2$ & EQ4c & ISO2 \\
\hline $\operatorname{Mean}_{\mathrm{m}}$ & $19.86 \pm 12.89$ & $20.17 \pm 13.05$ & $74.16 \pm 63.93$ & $74.91 \pm 63.41$ & $69.86 \pm 42.81$ & $70.08 \pm 42.55$ & $0.13 \pm 0.05$ & $0.13 \pm 0.10$ \\
\hline $\operatorname{Mean}_{\mathrm{O}}$ & $19.56 \pm 13.17$ & $19.56 \pm 13.17$ & $41.13 \pm 40.55$ & $41.13 \pm 40.55$ & $78.26 \pm 38.36$ & $78.26 \pm 38.36$ & $0.17 \pm 0.08$ & $0.17 \pm 0.08$ \\
\hline$r_{\mathrm{m}}$ & $16.81 \pm 0.24$ & $17.01 \pm 0.25$ & $37.35 \pm 1.48$ & $51.10 \pm 0.43$ & $44.75 \pm 0.62$ & $44.80 \pm 0.62$ & $0.13 \pm 0.15$ & $0.09 \pm 0.46$ \\
\hline$r_{\mathrm{O}}$ & $16.15 \pm 0.26$ & $16.15 \pm 0.26$ & $32.33 \pm 0.27$ & $32.33 \pm 0.27$ & $69.89 \pm 0.21$ & $69.89 \pm 0.21$ & $0.15 \pm 0.21$ & $0.15 \pm 0.21$ \\
\hline RMSE & 2.56 & 2.02 & 58.99 & 59.02 & 3.89 & 4.41 & 0.06 & 0.07 \\
\hline$R$ & 0.98 & 0.99 & 0.65 & 0.65 & 0.99 & 0.99 & 0.89 & 0.80 \\
\hline MBE & 0.30 & 0.61 & 33.07 & 33.78 & 0.22 & 0.47 & -0.03 & -0.04 \\
\hline GFE & 0.04 & 0.05 & 0.34 & 0.34 & 0.02 & 0.02 & 0.11 & 0.26 \\
\hline SS1 & 0.99 & 0.99 & 0.67 & 0.68 & 0.99 & 0.99 & 0.68 & 0.88 \\
\hline PF2 & 1.00 & 1.00 & 0.52 & 0.52 & 1.00 & 1.00 & 0.99 & 0.66 \\
\hline PF10 & 1.00 & 1.00 & 0.96 & 0.96 & 1.00 & 1.00 & 1.00 & 0.85 \\
\hline \multirow[t]{4}{*}{ NPOINTS } & 124 & 124 & 122 & 122 & 110 & 110 & 124 & 124 \\
\hline & \multicolumn{8}{|c|}{ Aerosol coarse mode } \\
\hline & \multicolumn{2}{|c|}{ HNO3 } & \multicolumn{2}{|c|}{ NH3 } & \multicolumn{2}{|c|}{$\mathrm{HCl}$} & \multicolumn{2}{|c|}{ PM } \\
\hline & EQ4c & ISO2 & EQ4c & $\mathrm{ISO} 2$ & $\mathrm{EQ} 4 \mathrm{c}$ & ISO2 & $\mathrm{EQ} 4 \mathrm{c}$ & ISO2 \\
\hline $\operatorname{Mean}_{\mathrm{m}}$ & $13.39 \pm 13.73$ & $9.55 \pm 12.34$ & $43.57 \pm 40.39$ & $40.76 \pm 41.05$ & $57.58 \pm 41.57$ & $38.29 \pm 41.11$ & $0.23 \pm 0.11$ & $0.23 \pm 0.14$ \\
\hline $\operatorname{Mean}_{\mathrm{O}}$ & $19.56 \pm 13.17$ & $19.56 \pm 13.17$ & $41.13 \pm 40.55$ & $41.13 \pm 40.55$ & $78.26 \pm 38.36$ & $78.26 \pm 38.36$ & $0.19 \pm 0.10$ & $0.19 \pm 0.10$ \\
\hline$r_{\mathrm{m}}$ & $5.79 \pm 0.76$ & $0.00 \pm 12.54$ & $35.09 \pm 0.27$ & $27.97 \pm 0.46$ & $39.17 \pm 0.48$ & $0.00 \pm 11.11$ & $0.20 \pm 0.22$ & $0.18 \pm 0.36$ \\
\hline$r_{\mathrm{O}}$ & $16.15 \pm 0.26$ & $16.15 \pm 0.26$ & $32.33 \pm 0.27$ & $32.33 \pm 0.27$ & $69.89 \pm 0.21$ & $69.89 \pm 0.21$ & $0.17 \pm 0.24$ & $0.17 \pm 0.24$ \\
\hline RMSE & 28.87 & 17.68 & 6.73 & 8.67 & 32.91 & 43.90 & 0.05 & 0.08 \\
\hline$R$ & 0.47 & 0.34 & 0.99 & 0.98 & 0.82 & 0.80 & 0.97 & 0.86 \\
\hline MBE & -2.09 & -10.01 & 3.08 & 0.24 & -20.58 & -35.75 & 0.04 & 0.04 \\
\hline GFE & 0.05 & 0.59 & 0.07 & 0.13 & 0.22 & 0.49 & 0.10 & 0.18 \\
\hline SS1 & 0.73 & 0.67 & 0.99 & 0.99 & 0.91 & 0.90 & 0.98 & 0.84 \\
\hline PF2 & 0.02 & 0.37 & 0.99 & 0.91 & 0.66 & 0.45 & 0.98 & 0.86 \\
\hline PF10 & 0.06 & 0.58 & 1.00 & 0.98 & 0.86 & 0.75 & 1.00 & 0.97 \\
\hline NPOINTS & 124 & 124 & 122 & 122 & 110 & 110 & 124 & 124 \\
\hline
\end{tabular}

close to the results of ISORROPIA II and EQUISOLV II (see also Supplement, Sect. S3.3).

The comparison of total nitrate and aerosol ammonium (Fig. 7) further reveals that also the semi-volatile compounds are rather well represented by EQSAM4clim, despite the underlying simplified analytical approach. Note that the lumped concentrations of the semi-volatile ions are shown only for the most complex cases, i.e. for the 10 sulfate neutral/poor cases (11-20). The common treatment among these EQMs is that both ammonium nitrate and ammonium chloride can be formed only when sulfate has been fully neutralised. A surplus of ammonia must exist to neutralise nitric acid and/or hydrochloric acid. Thus, their neutralisation also critically depends on the presence of the non-volatile, mineral cations, i.e. $\mathrm{Ca}^{2+}, \mathrm{Mg}^{2+}, \mathrm{K}^{+}, \mathrm{Na}^{+}$, which have been considered for certain cases (e.g. case 16). Depending on the sulfate loadings, these cations can practically determine the whole gasliquid-solid partitioning and the water uptake (Metzger et al., 2006).

\subsection{Field observations (MINOS campaign, 184 cases): ISORROPIA II}

To scrutinise further mineral-rich cases and to extend our model inter-comparison to size-resolved aerosol observations, we further apply both gas-aerosol partitioning schemes to (184) field measurements of the Mediterranean INtensive Oxidant Study (MINOS) that were obtained during a campaign in Crete in the period of 27 July to $25 \mathrm{Au}-$ gust 2001 (Lelieveld et al., 2002; Salisbury et al., 2003). Figures 8 and 9 compare the fine- and coarse-mode total particulate matter $\left[\mu \mathrm{mol} \mathrm{m}^{-3}\right.$ (air)], the predicted associated water mass $\left[\mathrm{g} \mathrm{m}^{-3}\right.$ (air)] and the residual gases $\left[\mu \mathrm{mol} \mathrm{m}{ }^{-3}(\right.$ air $\left.)\right]$, i.e. $\left[\mathrm{NH}_{3}\right]_{(\mathrm{g})},\left[\mathrm{HNO}_{3}\right]_{(\mathrm{g})},[\mathrm{HCl}]_{(\mathrm{g})}$ obtained for EQSAM4clim from Eqs. (6)-(12) with the results of ISORROPIA II and the MINOS observations, following Metzger et al. (2006). For a general description of the measurements and the modelling set-up we refer to Metzger et al. (2006). Here we apply both gas-aerosol partitioning models at the same level of complexity by considering the ammonium-sulfate-nitrate-chloride-sodiumcalcium-magnesium-potassium-water system, i.e. F4 and 


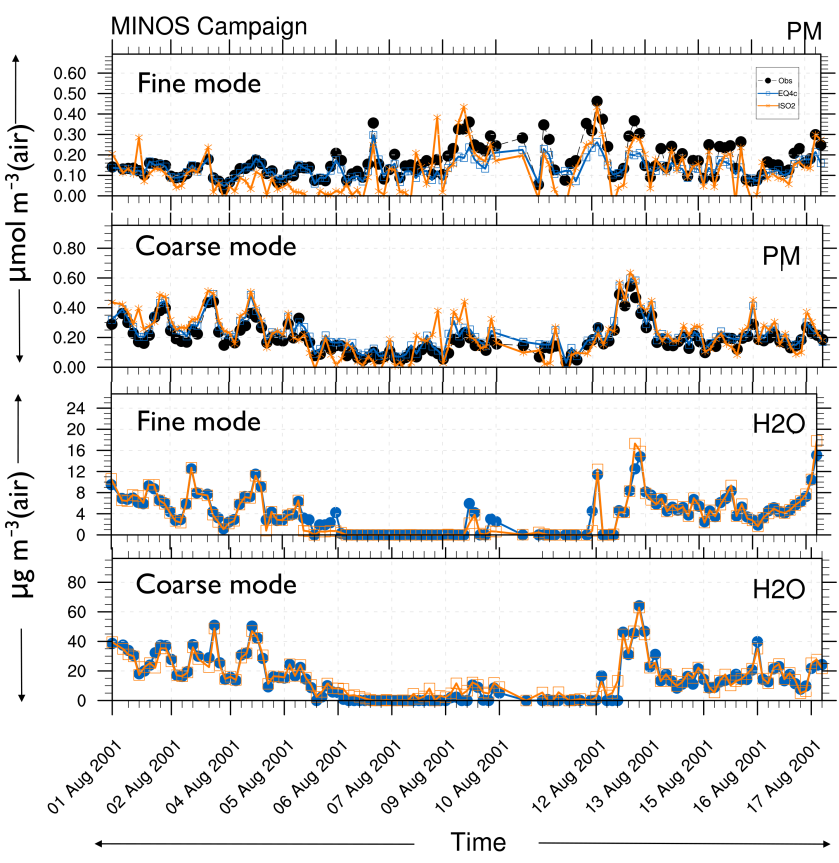

Figure 8. Observed and simulated total particulate matter $\left[\mu \mathrm{molm} \mathrm{m}^{-3}\right.$ (air)] and the predicted associated water mass $\left[\mu \mathrm{g} \mathrm{m}^{-3}\right.$ (air)] for the observed aerosol fine and coarse modes; EQSAM4clim (EQ4c), ISORROPIA II (ISO2), MINOS observations (black circles). This figure is extended to various other aerosol properties by Figs. S8 and S9 in the Supplement.

C4 in Table 1 of Metzger et al. (2006). Note that we omit here organic compounds for a consistent model inter-comparison, despite their relevance for the absolute comparison with observations. We refer to Metzger et al. (2006) for the influence of organic compounds on the ammonium partitioning during the MINOS campaign. Overall, also the size-resolved aerosol results of EQSAM4clim and ISORROPIA II are in close agreement with each other and reproduce field observations (see Table 5 for the statistics and Appendix $\mathrm{C}$ for the evaluation metrics and the additional comparison in the Supplement, Sect. S3.4).

\subsection{EMAC vs. satellite and AERONET observations}

To extend the model inter-comparison of EQSAM4clim and ISORROPIA II to global modelling applications, we use the atmospheric chemistry-climate model EMAC in a set-up following Abdelkader et al. (2015). Both gas-aerosol partitioning schemes are implemented in the GMXe aerosol microphysics submodule, as described in Pringle et al. (2010a, b) fully coupled with the EMAC chemistry, transport and radiation schemes. EQSAM4clim and ISORROPIA II are embedded in EMAC in exactly the same way, so that a direct comparison of the global modelling results can be made. Deviations can be fully explained by differences in the gas-aerosol partitioning and water uptake calculation approach.

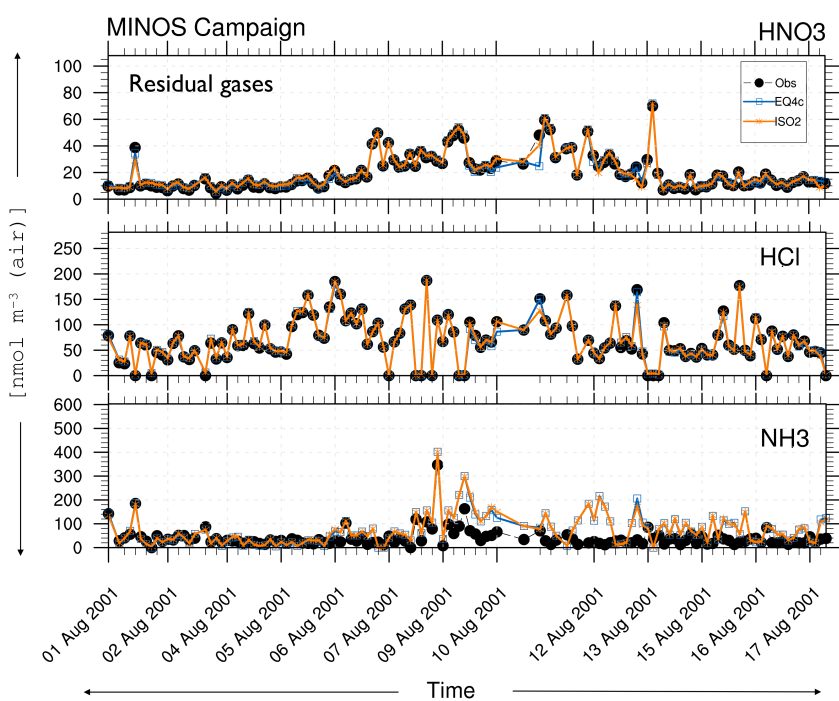

Figure 9. Residual gases $\left[\mu \mathrm{mol} \mathrm{m}{ }^{-3}\right.$ (air)] corresponding to Fig. 8.

To evaluate the EMAC results, we compare the aerosol optical depth (AOD) to three independent observational data sets, i.e. two satellites products, i.e. MODIS (MODerate resolution Imaging Spectroradiometer) and MISR (Multi-angle Imaging Spectro-Radiometer), and one ground-based product, i.e. from the AErosol RObotic NETwork (AERONET), http://aeronet.gsfc.nasa.gov. The AOD, or extinction coefficient, is a measure of radiation scattering and absorption at different wavelengths and sensitive to the gas-liquid-solid partitioning and aerosol hygroscopic growth. MODIS monitors the ambient AOD over the oceans and over a portion of the continents (see http://modis-atmos.gsfc.nasa.gov/). The MISR aerosol product is available globally. Both data products (and further information) are available from http://disc. sci.gsfc.nasa.gov/giovanni.

Figure 10 compares the model simulations and observations for the year 2005 (annual mean based on 5-hourly values). The upper left panel shows the EMAC results based on ISORROPIA II, the upper right panel shows the results based on EQSAM4clim; the results represent two independent simulations with an identical model set-up and spin-up. The AOD observations of MODIS and MISR are shown in the lower left and right panels, respectively. The qualitative comparison already shows that the differences between the two EMAC simulations and the satellite observations are larger than the differences between the two different EMAC simulations (despite the two distinct different gas-aerosol partitioning schemes). This result is supported by the AERONET observations, which are included in Fig. 10 as squares (with the same AOD colour scale). With respect to the observations, EMAC slightly underestimates the AOD, mainly over the open oceans, intense biomass burning and dust outbreaks, including the trans-Atlantic dust transport. Although the global dust belt seems to be captured rather well by the 


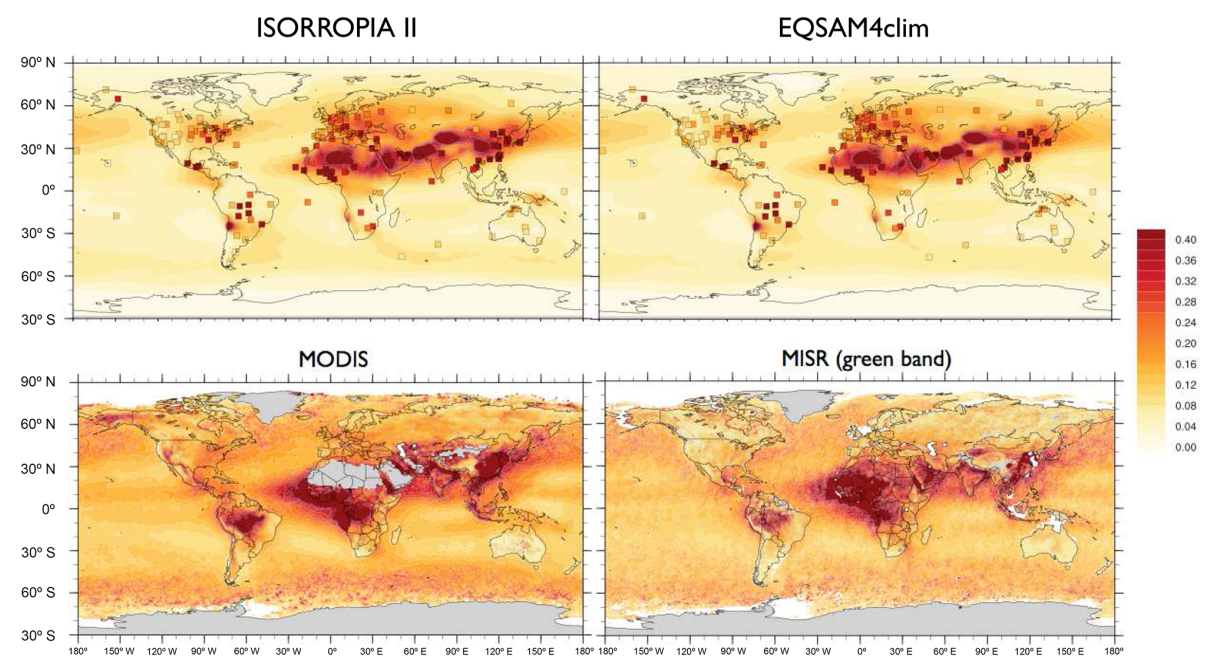

Figure 10. EMAC AOD vs. MODIS, MISR and AERONET (550 nm, annual mean 2005).

EMAC simulations, the current model set-up somewhat underestimates the AOD for the year 2005. The main reason is that we have limited the water uptake only to major inorganic salt compounds (those considered above in Sect. 3.4) for the sake of a consistent model inter-comparison of the two gasaerosol partitioning schemes. A more complete set-up that includes the water uptake of, e.g., biomass burning and organic compounds, will be presented separately. Nonetheless, considering the differences between the observations and the uncertainty of the AOD products, also these EMAC model predictions of EQSAM4clim and ISORROPIA II seem reasonable.

\section{Conclusions}

We have successfully extended the $v_{i}$ parameterisations from single to mixed solutions. The novelty of our single parameter framework is given by the fact that only one coefficient per compound is required to solve the multicomponent gasliquid-solid partitioning. Our results show that this approach is possible, since we use (i) a consistent set of equations that are all based on the mass fraction solubility $\chi_{\mathrm{s}}$ (Eq. A1) and $v_{i}$ (Sect. 2), and (ii) since we can assume $v_{i}$ to be constant (Sect. 2.1 and A4) for the entire range of water activity, $a_{\mathrm{w}}$ (for the $a_{\mathrm{w}}$ parameterisation see Eq. 5a of M2012 and Eq. A3). For semi-volatile compounds, we (iii) parameterise the temperature- and humidity-dependent equilibrium dissociation constant, $K_{\mathrm{p}, \mathrm{AN}}(T, \mathrm{RH})$, by substituting required activity coefficients with a new equation that is also only based on $\chi_{\mathrm{s}}$ and $v_{i}$ (Eqs. 1-5). The advantage is that $v_{i}$ can be accurately determined from one single data pair, i.e. the widely used solute's mass fraction solubility and the corresponding $a_{\mathrm{w}}-$ for the latter we use in this work RHD measurements (Sects. 2.1 and A4). With M2012 we have demonstrated that the $v_{i}$ concept allows one to accurately determine the aerosol water mass of binary solutions, $m_{\mathrm{w}, j}$, for a given solute concentration $n_{j(\mathrm{aq})}$. With this work we have shown that this is also true for the total aerosol water mass of mixed solutions, $m_{\mathrm{w}, \text { mix }}$ (Eq. 22), by using $\mu_{\mathrm{s}}$ (Eq. A3). Differences to reference calculations are basically caused by the assumptions made on the mixed solution RHD (Sect. 2.6), i.e. the different assumptions on the mutual deliquescence humidity range. Examples that can be verified with a pocket calculator are presented in the Supplement (Sect. S1) - they support the various box and global modelling results of Sects. 3 and S3.

\section{Data availability}

The underlying research data is available on request. 


\section{Appendix A: Single solute solutions}

\section{A1 Solute mass fraction, $\chi_{\mathrm{s}}$, and solute molality, $\mu_{\mathrm{s}}$}

The relation between solute mass fraction $\chi_{\mathrm{s}}$ and solute molality $\mu_{\mathrm{s}}$ is central in our mixed solution parameterisation framework (Sect. 2). Both can be expressed through each other (see, e.g., Eq. A11 of M2012). The solute mass fraction, $\chi_{\mathrm{s}}[-]$, is defined as the mass $[\mathrm{kg}]$ of solute, $m_{\mathrm{s}}=$ $n_{\mathrm{s}} \times M_{\mathrm{s}}$, relative to the total mass $[\mathrm{kg}]$ of the solution composed out of the mass of solute $m_{\mathrm{s}}$ and water, $m_{\mathrm{w}}=n_{\mathrm{w}} \times M_{\mathrm{w}}$ :

$$
\begin{aligned}
& \chi_{\mathrm{s}}:=\frac{m_{\mathrm{s}}}{\left(m_{\mathrm{s}}+m_{\mathrm{w}}\right)}=\left(\frac{m_{\mathrm{w}}}{m_{\mathrm{s}}}+1\right)^{-1}=\left(\frac{n_{\mathrm{w}} \times M_{\mathrm{w}}}{n_{\mathrm{s}} \times M_{\mathrm{s}}}+1\right)^{-1} \\
& =\left(\frac{1}{M_{\mathrm{s}} \times \mu_{\mathrm{s}}}+1\right)^{-1}
\end{aligned}
$$

$n_{\mathrm{S}}$ and $n_{\mathrm{w}}[\mathrm{mol}]$ are the number of moles of solute and solvent (water), $M_{\mathrm{S}}$ and $M_{\mathrm{W}}\left[\mathrm{kg} \mathrm{mol}^{-1}\right]$ are the corresponding molar masses of the solute and water, respectively.

The solute molality is defined as the number of moles of solute per kilogram of water, i.e. $\mu_{\mathrm{s}}$ [mol(solute) $\left.\mathrm{kg}^{-1}\left(\mathrm{H}_{2} \mathrm{O}\right)\right]$. It can be expressed in terms of the solute mass fraction by

$\mu_{\mathrm{s}}:=\frac{n_{\mathrm{s}}}{1 \mathrm{~kg} \mathrm{H}_{2} \mathrm{O}}=\frac{n_{\mathrm{s}}}{m_{\mathrm{w}}}=\frac{n_{\mathrm{s}}}{n_{\mathrm{w}} \times M_{\mathrm{w}}}=\frac{1}{M_{\mathrm{s}} \times\left(1 / \chi_{\mathrm{s}}-1\right)}$.

$\mu_{\mathrm{s}}$ measurements, tabulated as a function of water activity $\left(a_{\mathrm{W}}\right)$, are used in atmospheric modelling under the assumption that $a_{\mathrm{w}}$ equals RH to obtain the single solute (partial) aerosol water mass that is in equilibrium with a given amount of the single solute, $n_{\mathrm{s}}$, at the given RH from Eq. (22); see Sect. 2.7. Under this assumption, $\mu_{\mathrm{s}}$ is a function of $\mathrm{RH}$, actually $a_{\mathrm{w}}$, but in any case a function of the available water vapour mass, $m_{\mathrm{w}}$, which is in equilibrium associated with the solute mass, $m_{\mathrm{s}}$. This illustrated in Figs. A1 and A2 for several electrolytes used in this work; the solid lines refer to $\mu_{\mathrm{s}}$ measurements, the dotted lines to a parameterisation; see Sect. A2. Since for atmospheric applications, the aerosol associated water mass depends on the available water vapour mass, M2012 have expressed the single solute molality as a function of RH and a solute-specific coefficient, $v_{i}$. The M2012 concept is summarised in the following and has been extended to mixed solutions in Sect. 2.

\section{A2 Parameterisation of $\mu_{\mathrm{s}}$ and $\chi_{\mathrm{s}}$}

The representation of water activity (M2012) relates $a_{\mathrm{w}}$ to the solute molality $\mu_{\mathrm{s}}$ through a single solute-specific constant, $v_{i}$. This is a major advantage compared to other parameterisations, because the number of unknowns is reduced to one. To extend the $v_{i}$ approach to mixed solutions we use the parameterisation of solute molality
$\mu_{\mathrm{S}}\left[\operatorname{mol}\left(\right.\right.$ solute) $\left.\mathrm{kg}^{-1}\left(\mathrm{H}_{2} \mathrm{O}\right)\right]$. Inverting Eq. (5a) of M2012 allows one to express $\mu_{\mathrm{s}}$ as a function of RH and $\nu_{i}$, with $a_{\mathrm{w}}:=\frac{\mathrm{RH}}{K_{\mathrm{e}}}$ :

$$
\mu_{\mathrm{s}}=\mu_{\mathrm{s}}^{\mathrm{o}} \times\left(\left[\frac{1}{\mu_{\mathrm{s}}^{\mathrm{o}} \times M_{\mathrm{w}} \times v_{i}} \times\left(\frac{K_{\mathrm{e}}}{\mathrm{RH}}-A\right)\right]^{\frac{1}{v_{i}}}-B\right)
$$

The equivalent expression for $\chi_{\mathrm{s}}[-]$ is given by inserting Eq. (A3) in Eq. (A1).

$\mu_{\mathrm{s}}^{\mathrm{o}}=1\left[\mathrm{~mol} \mathrm{~kg}^{-1}\right]$ denotes a reference to match units. $M_{\mathrm{w}}\left[\mathrm{kg} \mathrm{mol}^{-1}\right]$ is the molar mass of water and $v_{i}$ a single solute-specific constant. $K_{\mathrm{e}}$ denotes the Kelvin term (see Sect. A5) and depends on the mass equivalent hygroscopic growth factor, GF (see Sect. A6). The terms $A$ and $B$ are defined by M2012; see their Eqs. (2) and (3) and are slightly revised (further simplified) in the following.

\section{A3 Parameterisation of $A$ and $B$ terms}

To break down the thermodynamics as much as possible, we use a simplified representation of the $A$ and $B$ terms compared to M2012. Throughout this work, we use a $B$ term that has been empirically determined to be a function of $v_{i}$ with the constraint that $A:=1$. Here, $B$ is expressed in terms of the solute mass fraction $\chi_{\mathrm{s}}$ and defined as

$B:=\chi_{\mathrm{s}}^{\left[\frac{1}{1+v_{i}+\chi_{\mathrm{s}}}\right]}$.

To express $\chi_{\mathrm{s}}$ in Eq. (A4), we use Eq. (A3) for $\mu_{\mathrm{s}}$ (right term of Eq. A1).

\section{A4 Relative humidity of deliquescence (RHD)}

To pre-determine $v_{i}$ for our mixed solutions framework we use RHD measurements at $T_{\mathrm{o}}=298[\mathrm{~K}]$; see Sects. 2.1 and 2.3 in M2012. To solve our mixed solution framework we calculate the temperature dependency from Wexler and Potukuchi (1998):

$\operatorname{RHD}(T)=\operatorname{RHD}\left(T_{\mathrm{o}}\right) \times \exp \left[T_{\text {coef }} \times\left(\frac{1}{T}-\frac{1}{T_{\mathrm{o}}}\right)\right]$.

The RHD measurements at $T_{\mathrm{O}}=298$ and the corresponding temperature coefficients are taken from Fountoukis and Nenes (2007) and listed in Table 1.

To determine $v_{i}$, we solve Eq. (5b) of M2012, which we include here for completeness:

RHD $=$

$$
\frac{K_{\mathrm{e}}}{\left(A+\mu_{\mathrm{s}}^{\mathrm{o}} \times M_{\mathrm{W}} \times v_{i} \times\left[\frac{1}{\mu_{\mathrm{s}}^{\mathrm{o}}} \times \frac{1}{M_{\mathrm{s}} \times\left(1 / w_{\mathrm{s}}-1\right)}+B\right]^{\nu_{i}}\right)} .
$$

The RHD [-] describes the point of water activity, $a_{\mathrm{w}}[-]$, where a solution is saturated. Any excess of solute leads to solute precipitation and co-existence of a solid and liquid 


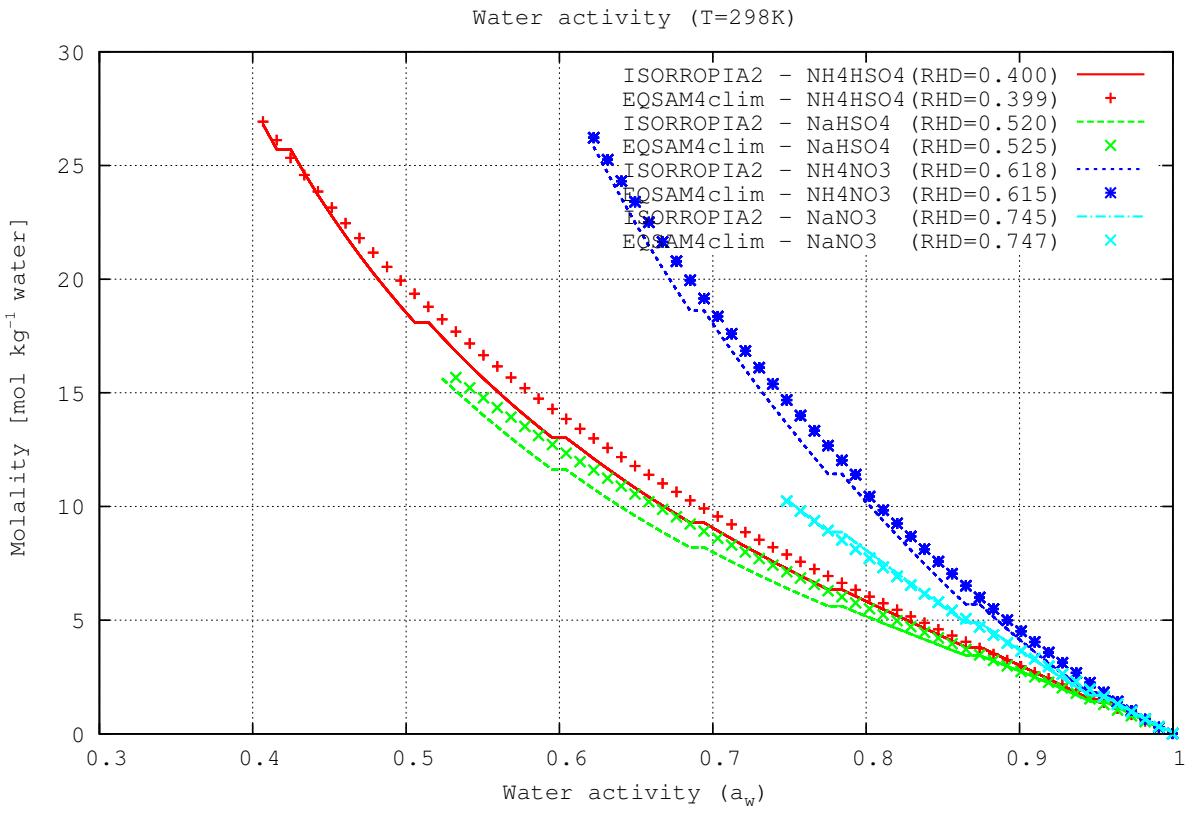

Figure A1. Single solute molality as a function of water activity for several electrolytes: $\left(\mathrm{NH}_{4}\right) \mathrm{HSO}_{4}, \mathrm{NaHSO}_{4}, \mathrm{NH}_{4} \mathrm{NO}_{3}, \mathrm{NaNO}_{3}($ at $T=$ $298.15 \mathrm{~K}$ ) calculated with EQSAM4clim from Eqs. (A3) and (A6) compared to tabulated molality and RHD measurements of ISORROPIA II used to determine $v_{i}$.

Table A1. List of names and abbreviations.

\begin{tabular}{ll}
\hline Abbreviation & Name \\
\hline AOD & Aerosol Optical Depth \\
AERONET & AErosol RObotic NETwork (http://aeronet.gsfc.nasa.gov) \\
CNN & cloud condensation nuclei \\
CPU & computational performance unit \\
EQMs & Thermodynamic equilibrium models \\
E-AIM & (Wexler and Clegg, 2002), http://www.aim.env.uea.ac.uk/aim/aim.php \\
EQSAM & Equilibrium Simplified Aerosol Model (Metzger et al., 2002b) \\
EQSAM4clim & Equilibrium Simplified Aerosol Model (Version 4) for Climate Simulations (this work) \\
EQUISOLV II & Jacobson (1999) \\
EMAC & Atmospheric Chemistry-climate model ECHAM5/MESSy2.50 (Abdelkader et al., 2015) \\
GMXe & Global Modal-aerosol eXtension (Pringle et al., 2010a, b) \\
ISORROPIA II & Fountoukis and Nenes (2007) \\
MODIS & MODerate resolution Imaging Spectroradiometer (http://modis-atmos.gsfc.nasa.gov/) \\
MISR & Multi-angle Imaging Spectro-Radiometer (http://disc.sci.gsfc.nasa.gov/giovanni) \\
MINOS & Mediterranean INtensive Oxidant Study (Lelieveld et al., 2002; Salisbury et al., 2003) \\
NRO & neutralisation reaction order (Sect. 2.3) \\
\hline M2012 & Metzger et al. (2012) \\
SP2006 & Seinfeld and Pandis (2006) \\
\hline
\end{tabular}

phase (see Sects. 2.6 and 2.7). At solute saturation, the solute mass fraction (Eq. A1) is measured by the widely used mass fraction solubility $w_{\mathrm{s}}[-]$. Since the saturation molality $\mu_{\mathrm{s} \text {, sat }}$ and the mass fraction solubility $w_{\mathrm{s}}$ are related through Eq. (A2), i.e. $\mu_{\mathrm{s}, \mathrm{sat}}=\frac{1}{M_{\mathrm{s}} \times\left[1 / w_{\mathrm{s}}-1\right]}, \mathrm{M} 2012$ express the RHD in terms of $w_{\mathrm{s}}$ and a single solute-specific coefficient, $v_{i}$. For a given $w_{\mathrm{s}}$ and RHD data pair, $v_{i}$ can be accurately determined if Eq. (A6) is solved with a root-finding method (e.g. bisection). This procedure has been detailed in M2012 and only requires one data pair. To pre-determine $v_{i}$ for all salt compounds used in this work, we follow M2012 and use the $w_{\mathrm{s}}$ and RHD measurements at $T_{\mathrm{o}}=298[\mathrm{~K}]$. The pre-determined $v_{i}$ values used are included in Table 1. To solve our mixed solutions framework we assume $v_{i}$ constant and independent of the temperature. Therefore, Eq. (A6) is not needed. It could be used during runtime, e.g. within 
Table A2. List of greek symbols.

\begin{tabular}{lll}
\hline Greek symbol & Name & Unit \\
\hline$\nu_{i}$ & solute-specific constant (introduced by M2012) & {$[-]$} \\
\hline$v_{\mathrm{S}}$ & stoichiometric coefficient of solute (tion-pair) & {$[-]$} \\
$\mu_{\mathrm{S}}$ & molality of solute & {$\left[\mathrm{mol} \mathrm{kg}^{-1}\left(\mathrm{H}_{2} \mathrm{O}\right)\right]$} \\
$\mu_{\mathrm{S}}^{\mathrm{O}}$ & reference molality of 1 mole of solute (considering stoichiometry) & {$\left[\mathrm{mol} \mathrm{kg}^{-1}\left(\mathrm{H}_{2} \mathrm{O}\right)\right]$} \\
$\mu_{\mathrm{S}}^{\text {sat }}$ & saturation molality of solute & {$\left[\mathrm{mol} \mathrm{kg}^{-1}\left(\mathrm{H}_{2} \mathrm{O}\right)\right]$} \\
$\rho_{\mathrm{S}}$ & density of solute & {$\left[\mathrm{kg} \mathrm{m}^{-3}\right]$} \\
$\rho_{\mathrm{W}}$ & density of water & {$\left[\mathrm{kg} \mathrm{m}^{-3}\right]$} \\
$\sigma_{\mathrm{sol}}$ & surface tension of the solution droplet & {$\left[\mathrm{J} \mathrm{m}^{-2}\right]$} \\
$\chi_{\mathrm{s}}$ & solute mass fraction, referring to the solute's dry mass & {$[-]$} \\
$\chi_{\mathrm{S}}^{\text {sat }}$ & solute mass fraction, referring to the solute's dry mass at saturation & {$[-]$} \\
\hline sat & superscript, indicator for saturation & \\
$(\mathrm{cr})$ & subscript, phase indicator for anhydrous (solid = crystalline $=$ cr) phase & \\
$($ aq) & subscript, phase indicator for aqueous phase & \\
$(\mathrm{g})$ & subscript, phase indicator for gas phase & \\
\hline
\end{tabular}

Table A3. List of symbols.

\begin{tabular}{|c|c|c|}
\hline Symbol & Name & Unit \\
\hline$A$ & $A$ term of Eq. (A4), introduced with Sect. A3 & {$[-]$} \\
\hline$B$ & $B$ term of Eq. (A4), introduced with Sect. A3 & {$[-]$} \\
\hline$a_{\mathrm{w}}$ & water activity (Raoult-term) & {$[-]$} \\
\hline$D_{\mathrm{s}}$ & dry droplet diameter of the solute & {$[\mathrm{m}]$} \\
\hline$D_{\text {wet }}$ & wet droplet diameter of the solution & {$[\mathrm{m}]$} \\
\hline$K_{\mathrm{e}}$ & surface or Kelvin term of the solution & {$[-]$} \\
\hline$m_{\mathrm{S}}$ & crystalline mass of solute & {$[\mathrm{kg}]$} \\
\hline$m_{\mathrm{W}}$ & aqueous mass of water (solvent) & {$[\mathrm{kg}]$} \\
\hline$M_{\mathrm{S}}$ & molar mass of solute & {$\left[\mathrm{kg} \mathrm{mol}^{-1}\right]$} \\
\hline$M_{\mathrm{W}}$ & molar mass of water & {$\left[\mathrm{kg} \mathrm{mol}^{-1}\right]$} \\
\hline$n_{\mathrm{S}}$ & moles of solute & {$[\mathrm{mol}]$} \\
\hline$\sum_{i} n_{i}$ & summation over all moles of solutes & [mol] \\
\hline$n_{\mathrm{W}}$ & moles of water & {$[\mathrm{mol}]$} \\
\hline GF & Growth Factor & {$[-]$} \\
\hline RH & relative humidity in percent (as used in the text) & {$[\%]$} \\
\hline RH & fractional relative humidity (as used in equations) & {$[-]$} \\
\hline RHD & fractional relative humidity of deliquescence & {$[-]$} \\
\hline$s$ & saturation ratio & {$[-]$} \\
\hline$S$ & supersaturation & {$[-]$} \\
\hline$S_{\mathrm{c}}$ & critical supersaturation in percent & {$[\%]$} \\
\hline$T_{\text {coef }}$ & dimensionless temperature coefficients for the RHD & {$[-]$} \\
\hline$T_{\mathrm{O}}$ & reference temperature in Kelvin & {$[298.15 \mathrm{~K}]$} \\
\hline$T$ & temperature in Kelvin & {$[\mathrm{K}]$} \\
\hline$w_{\mathrm{s}}$ & mass fraction solubility, referring to the solute's dry mass required for saturation & {$[-]$} \\
\hline$W_{\mathrm{s}}$ & mass fraction solubility, referring to the solute's dry mass required for saturation & {$[\%]$} \\
\hline tCAT & total cations (for chemical domains; Sect. 2.2) & {$\left[\mathrm{mol} \mathrm{m}^{-3}\right.$ (air)] } \\
\hline
\end{tabular}




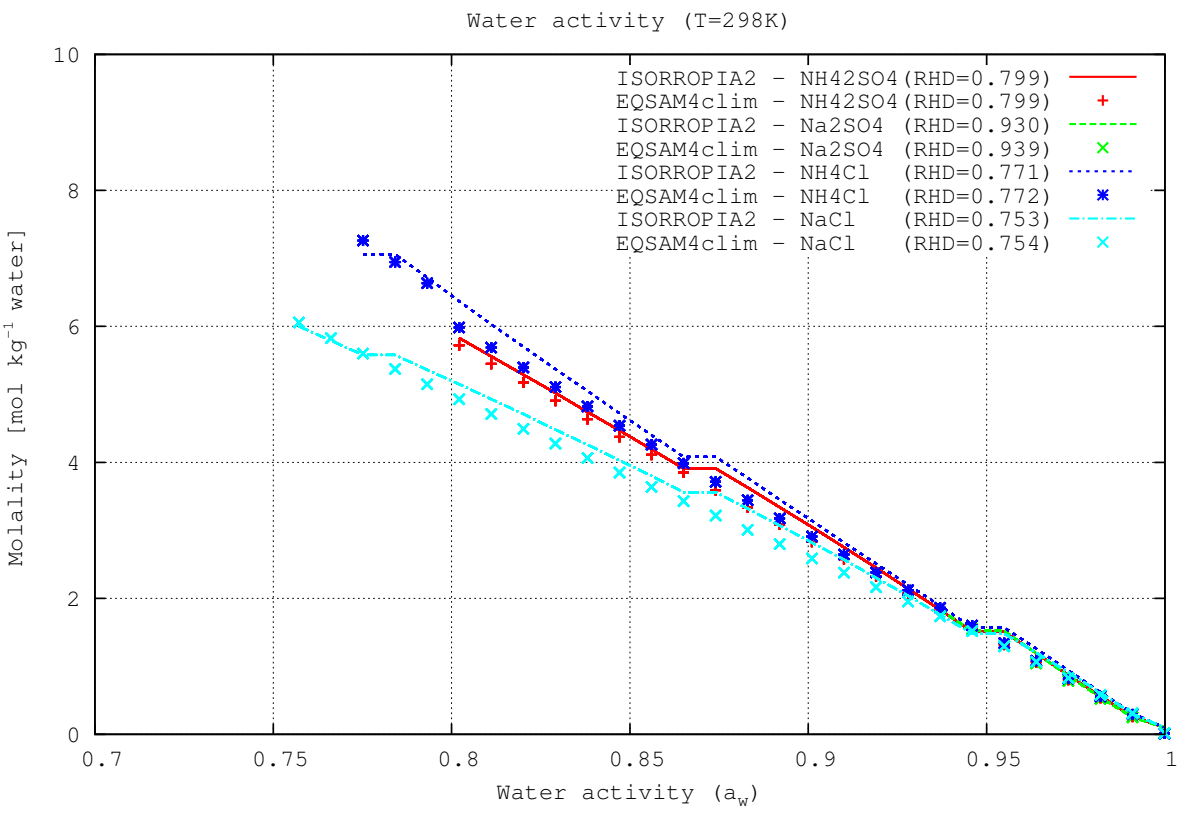

Figure A2. Figure A1 continued for $\left(\mathrm{NH}_{4}\right)_{2} \mathrm{SO}_{4}, \mathrm{Na}_{2} \mathrm{SO}_{4}, \mathrm{NH}_{4} \mathrm{Cl}, \mathrm{NaCl}$ (at $T=298.15 \mathrm{~K}$ ).

EQSAM4clim (see Sect. B), to determine $v_{i}$ for different $T$. But this is beyond the scope of this work, since the reference models currently available to evaluate our mixed solution parameterisation framework are also based on water activity data at $T_{\mathrm{o}}$.

\section{A5 Kelvin term}

The parameterisation of solute molality, $\mu_{\mathrm{S}}$ (introduced by M2012), depends on the so-called Kelvin term, $K_{\mathrm{e}}[-]$ (Eq. A3), which can be expressed in terms of the growth factor, $g_{\mathrm{s}}$ :

$$
\begin{aligned}
& K_{\mathrm{e}}=\exp \left(\frac{4 \times M_{\mathrm{w}} \times \sigma_{\mathrm{sol}}}{R \times T \times \rho_{\mathrm{w}} \times D_{\mathrm{w}}}\right) \\
& =\exp \left(\frac{4 \times M_{\mathrm{w}} \times \sigma_{\mathrm{sol}}}{R \times T \times \rho_{\mathrm{w}} \times g_{\mathrm{s}} \times D_{\mathrm{s}}}\right)
\end{aligned}
$$

$\sigma_{\text {sol }}\left[\mathrm{J} \mathrm{m}^{-2}\right]$ denotes the RH-dependent surface tension of the solution droplet. $T[\mathrm{~K}]$ is the droplet temperature, $R=8.314409\left[\mathrm{~J} \mathrm{~mol}^{-1} \mathrm{~K}^{-1}\right]$ the ideal gas constant, $M_{\mathrm{w}}\left[\mathrm{kg} \mathrm{mol}^{-1}\right]$ the molar mass and $\rho_{\mathrm{w}}\left[\mathrm{kg} \mathrm{m}^{-3}\right]$ the density of water. $D_{\text {wet }}$ and $D_{\mathrm{s}}[\mathrm{m}]$ are the ambient and dry droplet diameter, respectively.

\section{A6 Growth factor}

Equation (A7) depends on the RH-dependent (mass equivalent) hygroscopic growth factor, $g_{\mathrm{s}}[-]$. We assume a geometric diameter $=$ mass equivalent diameter of a compact spherical droplet and a constant surface tension of pure water droplets, i.e. $\sigma_{\text {sol }}=0.0761\left[\mathrm{~J} \mathrm{~m}^{-2}\right]$. We further assume that the droplet temperature is in equilibrium with the ambient air, and we consider the widely used volume additivity. Then, the volume of the solution droplet can be expressed as the sum of volumes of the dry solute and that of the associated pure (aerosol) water contained in the droplet. The ambient diameter, $D_{\text {wet }}$, of the droplet can therefore be expressed in terms of the solute dry diameter, $D_{\mathrm{s}}$, and $g_{\mathrm{s}}$ :

$$
\begin{aligned}
& g_{\mathrm{s}}:=\frac{D_{\mathrm{wet}}}{D_{\mathrm{s}}}=\left(\frac{V_{\mathrm{w}}+V_{\mathrm{s}}}{V_{\mathrm{s}}}\right)^{1 / 3}=\left(\frac{V_{\mathrm{w}}}{V_{\mathrm{s}}}+1\right)^{1 / 3} \\
& =\left(\frac{\rho_{\mathrm{s}} \times m_{\mathrm{w}}}{\rho_{\mathrm{w}} \times m_{\mathrm{s}}}+1\right)^{1 / 3}=\left(\frac{\rho_{\mathrm{s}}}{M_{\mathrm{s}} \times \rho_{\mathrm{w}} \times \mu_{\mathrm{s}}}+1\right)^{1 / 3} .
\end{aligned}
$$

$V_{\mathrm{w}}+V_{\mathrm{s}}\left[\mathrm{m}^{3}\right]$ is the total volume of the wet droplet with $\quad V_{\mathrm{s}}=m_{\mathrm{s}} / \rho_{\mathrm{s}}=n_{\mathrm{s}} M_{\mathrm{s}} / \rho_{\mathrm{s}} \quad$ and $\quad V_{\mathrm{w}}=m_{\mathrm{w}} / \rho_{\mathrm{w}}=$ $n_{\mathrm{w}} M_{\mathrm{w}} / \rho_{\mathrm{w}}\left[\mathrm{m}^{3}\right]$, i.e. the volumes of the initially dry solute and the associated pure water, respectively. $m_{\mathrm{S}}$ and $m_{\mathrm{w}}[\mathrm{kg}]$ denote the corresponding solute and water masses, $M_{\mathrm{S}}$ and $M_{\mathrm{W}}\left[\mathrm{kg} \mathrm{mol}^{-1}\right]$ the molar masses, $n_{\mathrm{S}}$ and $n_{\mathrm{w}}[\mathrm{mol}]$ the number of moles, and $\rho_{\mathrm{s}}$ and $\rho_{\mathrm{w}}\left[\mathrm{kg} \mathrm{m}^{-3}\right]$ the densities, respectively.

\section{Appendix B: EQSAM4clim}

We apply our new mixed solution parameterisation framework (Sect. 2) in the EQuilibrium Simplified Aerosol Model V4 for climate simulations. Selected results are shown in Sect. 3, which are extended in the Supplement. EQSAM4clim aims at accurate but numerically efficient water uptake calculations that are applicable to high-resolution or long-term modelling at climate timescales, i.e. decades to centuries. In contrast to previous EQSAM versions and 

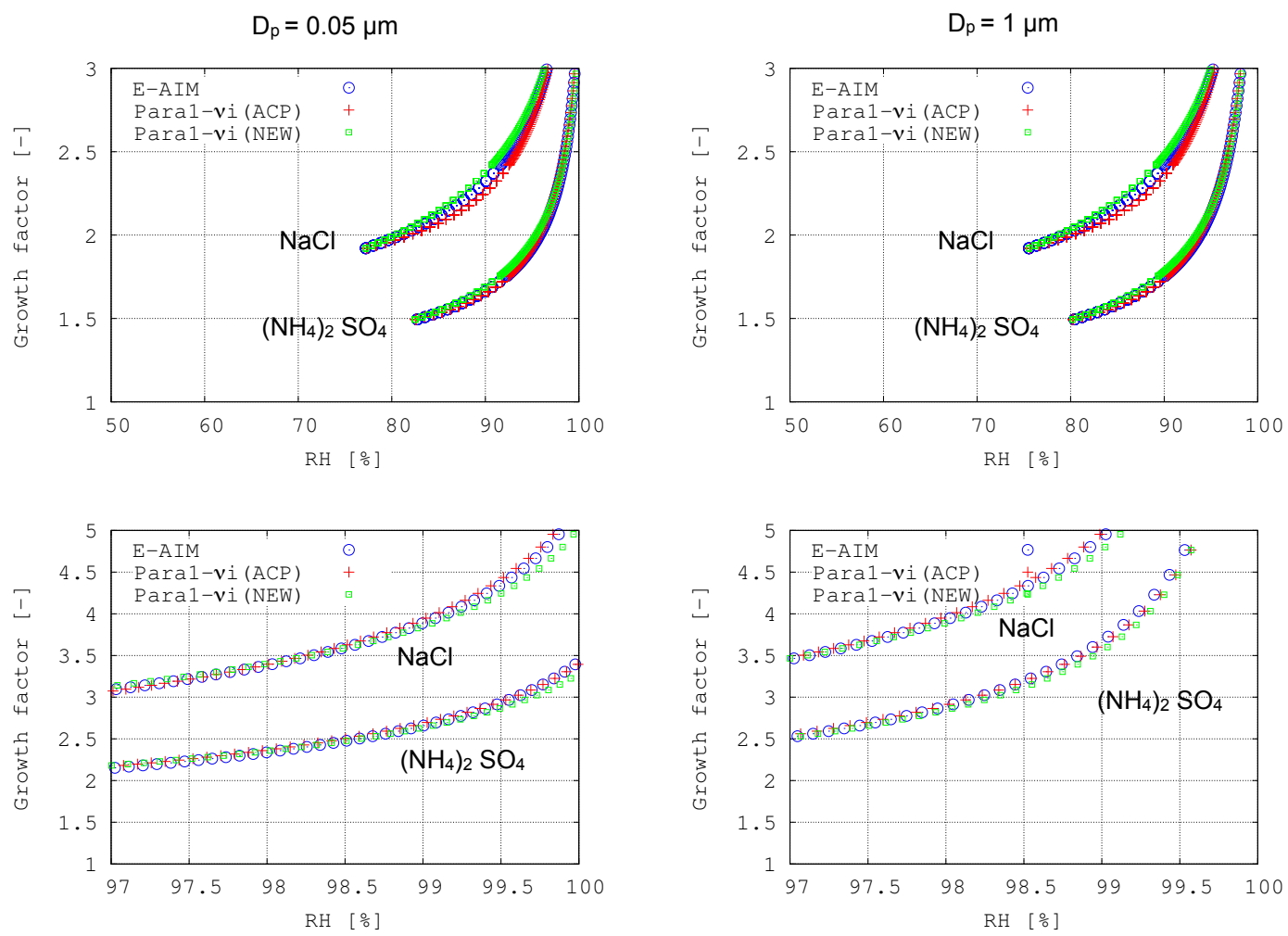

Figure B1. Growth factor of pure $\mathrm{NaCl}_{(\mathrm{cr})}$ and $\left(\mathrm{NH}_{4}\right)_{2} \mathrm{SO}_{4(\mathrm{cr})}$ particles with a dry diameter $D_{\mathrm{S}}=0.05[\mu \mathrm{m}](\mathrm{UL})$ and $D_{\mathrm{S}}=1[\mu \mathrm{m}](\mathrm{UR})$ for $\mathrm{RH} \leq 97$ [\%]. Lower panels show the corresponding values within the subsaturated regime, i.e. $97 \leq \mathrm{RH} \leq 100$ [\%]. The results of the parameterisation used by EQSAM4clim (labelled NEW) are compared to our ACP(M2012) water activity, $a_{\mathrm{w}}$-parameterisation (labelled ACP, i.e. Para1 of Table 1 in M2012). The comparison includes the results of E-AIM and extends the corresponding figures of M2012.

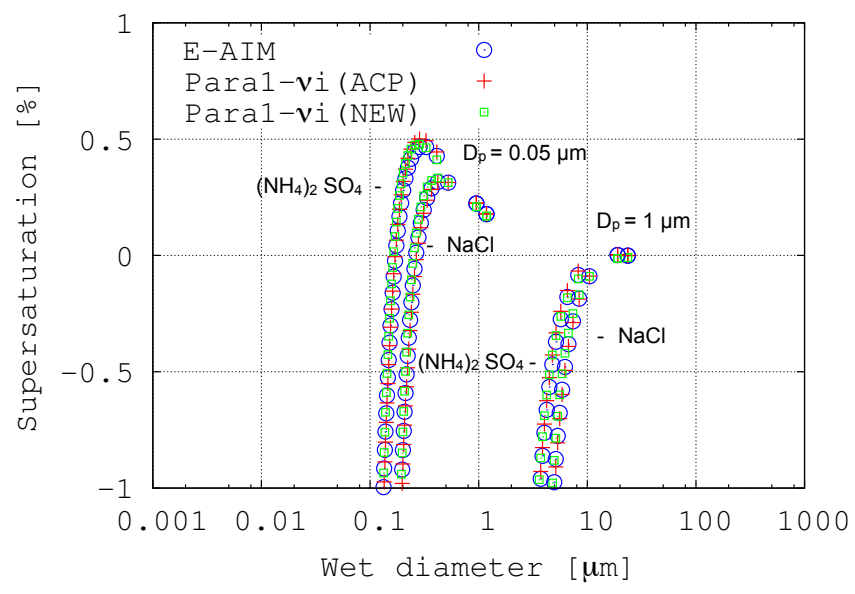

Figure B2. Wet particle diameter, $D_{\text {wet }}$, as a function of supersaturation for pure $\mathrm{NaCl}$ and $\left(\mathrm{NH}_{4}\right)_{2} \mathrm{SO}_{4}$ aerosols with different dry diameters, i.e. $D_{\mathrm{S}}=0.05$ and $D_{\mathrm{S}}=1[\mu \mathrm{m}]$ as shown in Fig. 5 of M2012. $S$ is defined as $S=(s-1) \times 100[\%]$; $s$ is the saturation $=$ fractional $\mathrm{RH}$.

all other thermodynamic gas-liquid-solid aerosol partitioning models, EQSAM4clim considers a consistent, simplified mixed solution parameterisation, which can be solved ana- lytically. Our key equation of solute molality, $\mu_{\mathrm{s}}$, (Eq. A3), and the entire mixed solution phase partitioning (Sect. 2) can be solved analytically, even with a pen and pocket calculator as demonstrated in the Supplement (Sect. 1). EQSAM4clim (as all other EQSAM versions) builds on the fact that for atmospheric applications, $\mu_{\mathrm{s}}$ can be expressed as a function of relative humidity (RH); Sect. A2. This was first demonstrated by Metzger et al. (2002a) (based on Metzger et al., 1999; Metzger 2000, PhD Thesis, University of Utrecht, the Netherlands; http://adsabs.harvard.edu/abs/2000PhDT... ....328M; provided by the SAO/NASA Astrophysics Data System).

To solve our mixed solution framework, we express $g_{\mathrm{s}}$ in terms of $\mu_{\mathrm{s}}$ to reduce the number of unknowns to one, i.e. $v_{i}$; assuming the aerosol dry size $D_{\mathrm{s}}$, temperature $(T)$ and relative humidity $(\mathrm{RH})$ are prescribed (e.g. given during runtime as model input). Since $g_{\mathrm{s}}[-]$ is defined as the ratio of wet to dry droplet diameter, it can be expressed in terms of the solute molality (by using either Eq. A2 or Eq. A3). Due to its implicit character in $\mu_{\mathrm{s}}$, solving Eq. (A3) requires iterations. One can apply an efficient root finding algorithm, which converges quickly. Treating $K_{\mathrm{e}}$ and the $B$ term as perturbation, it is possible to truncate after the fourth iteration. Higher accuracy will not improve the results much further. 
For EQSAM4clim, we solve Eq. (A3) for a given aerosol composition, with $T$, RH and $D_{\mathrm{s}}$ as the unknown variables that are given at model input for each model grid box and time step. Note that we use the $K_{\mathrm{e}}$ term for Eq. (A3), so that EQSAM4clim compares to Paral of M2012 (see their Table 1).

We solve $\mu_{\mathrm{S}}$ for all compounds listed in Table 1 for a given RH from a two-step approach:

- Step one: $K_{\mathrm{e}}=1$, and $B=0$ to obtain the initial $\mu_{\mathrm{s}}$ from Eq. (A3).

- Step two, repeated three times: $\mu_{\mathrm{s}}$ from previous iteration is used to calculate $K_{\mathrm{e}}$ from Eq. (A7), $\chi_{\mathrm{s}}$ from Eq. (A1), $B$ from Eq. (A4). Then a new $\mu_{\mathrm{s}}$ is obtained from Eq. (A3).

Figures A1 and A2 show $\mu_{\mathrm{s}}$ obtained from Eq. (A3) (applied within EQSAM4clim) as a function of bulk water activity, i.e. $K_{\mathrm{e}}=1$ and $a_{\mathrm{w}}=\mathrm{RH}$, for major electrolytes (at $T=$ $298.15 \mathrm{~K}$ ). All single solute molalities compare well with the tabulated solute molality data (Sect. A1) used in ISORROPIA II (and other EQMs) for the entire $a_{\mathrm{w}}$-range: from the water activity at saturation, i.e. RHD, up to $a_{\mathrm{w}}=1$ (pure water). Furthermore, the results of M2012 can be reproduced with Eq. (A3) using the modified $B$-term, Eq. (A4) with $A=1$. Figure B1 compares the GF obtained with Eq. (A8) (marked as NEW) for pure $\mathrm{NaCl}_{(\mathrm{cr})}$ and $\left(\mathrm{NH}_{4}\right)_{2} \mathrm{SO}_{4}$ (cr) particles with a dry diameter $D_{\mathrm{s}}=0.05[\mu \mathrm{m}]$ and $D_{\mathrm{s}}=$ $1[\mu \mathrm{m}]$ against those of M2012 (marked as ACP(M2012) $=$ Para1) and E-AIM for the subsaturated $\mathrm{RH}$ regime with $\mathrm{RH} \leq 97$ [\%] (upper panels), and the subsequent regime, i.e. $97 \leq \mathrm{RH} \leq 100$ [\%] (lower panels). Figure B2 compares the corresponding wet particle diameter, $D_{\text {wet }}$, as a function of supersaturation (all at $T=298.15 \mathrm{~K}$ ); see description of Figs. 3, 4 and 5 of M2012.

Besides significant computational speed-up, another advantage is that our framework minimises the number of thermodynamic data that are typically required, while it enables greater flexibility with respect to the extension to other compounds, not considered in this evaluation. EQSAM4clim (v09) is limited to the same salt compounds as ISORROPIA II, so that the single solute parameter $v_{i}$, which is required to solve the single solute molality, $\mu_{\mathrm{s}}$ (Eq. A3), can be determined from a single reference data pair (Sect. A4). In addition, most computations are comprehensive and complex. In contrast, the numerical algorithm of EQSAM4clim is simple and easier to verify, since it does not involve any numerical solution or iteration to solve the gas-liquid-solid partitioning for the reasons summarised in Sect. 2.7.

EQSAM4clim has the advantage of being a short Fortran 90 (f90) code with approximately 850 lines, including comments (or 8 pages); see Fig. S1 in the Supplement for a sample. Figure S2.1 in the Supplement shows the flow chart of processes and operations; the computational algorithm is summarised in the Supplement (Sect. S2). For compari- son, the gas-aerosol partitioning routine ISORROPIA II, also used in EMAC counts roughly 36300 lines (or approx. 360 pages). For comparison, this is about one-third of the source code of the EMAC climate model core (ECHAM5.3.02), which has about 120000 lines of f90 code (both including comments). Last but not least, due to its analytical structure the additional computational costs of EQSAM4clim are negligible for our climate applications, which will be detailed and presented separately.

\section{Appendix C: Evaluation metrics}

- RMSE - root mean square error between the model $(\mathrm{m})$ and the observations $\left({ }_{\mathrm{o}}\right)$ :

$$
\operatorname{RMSE}=\sqrt{\frac{1}{N} \sum\left(X_{\mathrm{m}}-X_{\mathrm{o}}\right)^{2}}
$$

- $\sigma$ - standard deviation of the model $\left(\sigma_{\mathrm{m}}\right)$ and the observed $\left(\sigma_{\mathrm{m}}\right)$ value:

$$
\sigma=\sqrt{\frac{1}{N} \sum_{i=1}^{N}\left(X_{i}-\bar{X}\right)^{2}}, \text { where } \bar{X}=\frac{1}{N} \sum_{i=1}^{N} X_{i}
$$

- $R$ - correlation coefficient between the model $(\mathrm{m})$ and the observations $\left({ }_{0}\right)$ :

$$
R=\frac{\sum_{i=1}^{N}\left(X_{i}^{\mathrm{m}}-\overline{X^{\mathrm{m}}}\right)\left(X_{i}^{\mathrm{o}}-\overline{X^{\mathrm{o}}}\right)}{\sum_{i=1}^{N}\left(X_{i}^{\mathrm{m}}-\overline{X^{\mathrm{m}}}\right)^{2} \sum_{i=1}^{N}\left(X_{i}^{\mathrm{o}}-\overline{X^{\mathrm{o}}}\right)^{2}}
$$

- MBE - mean bias error between the model $(\mathrm{m})$ and the observations $\left({ }_{\mathrm{o}}\right)$ :

$$
\mathrm{MBE}=\frac{1}{N} \sum\left(X_{\mathrm{m}}-X_{\mathrm{o}}\right)
$$

- $r$-geometric mean of the model $\left(\mathrm{r}_{\mathrm{m}}\right)$ and the observations $\left(\mathrm{r}_{\mathrm{o}}\right)$ :

$$
r=\sqrt[n]{\Pi_{i=1}^{N} X}
$$

- GFE - growth factorial error:

$$
\mathrm{GFE}=\frac{1}{N} \sum \frac{\left|\left(X_{\mathrm{m}}-X_{\mathrm{o}}\right)\right|}{X_{\mathrm{m}}+X_{\mathrm{o}}}
$$


- SS1 - skill score between the model $(\mathrm{m})$ and the observations $(\mathrm{o})$ :

$$
\begin{aligned}
& \mathrm{SS} 1=\frac{4(1+R)}{\left(\sigma_{f}+1 / \sigma_{f}\right)^{2}\left(1+R_{0}\right)}, \\
& \text { where } \quad \sigma_{f}=\frac{\sigma_{\mathrm{o}}}{\sigma_{\mathrm{m}}} \quad R_{0}=0.0
\end{aligned}
$$

$\mathrm{PF} 2$ is fraction of the number of points within a factor of 2 of the observations, PF10 is fraction of the number of points within a factor of 10 of the observations, and NPoints is the number of points used. 


\section{The Supplement related to this article is available online at doi:10.5194/acp-16-7213-2016-supplement.}

Acknowledgements. This work was supported the European Research Council under the European Union's Seventh Framework Programme (FP7/2007-2013)-ERC grant agreement no. 226144 through the C8-Project. All EMAC simulations have been carried out on the Cy-Tera Cluster, operated by the Cyprus Institute (CyI) and co-funded by the European Regional Development Fund and the Republic of Cyprus through the Research Promotion Foundation (Project Cy-Tera NEA-YПО $\Delta O M H / \Sigma T$ TPTH/0308/31). We thank the measurement and model development teams for providing the observations and reference models used in this study.

The article processing charges for this open-access publication were covered by the Max Planck Society.

Edited by: M. Kanakidou

\section{References}

Abdelkader, M., Metzger, S., Mamouri, R. E., Astitha, M., Barrie, L., Levin, Z., and Lelieveld, J.: Dust-air pollution dynamics over the eastern Mediterranean, Atmos. Chem. Phys., 15, 91739189, doi:10.5194/acp-15-9173-2015, 2015.

Amundson, N. R., Caboussat, A., He, J. W., Martynenko, A. V., Savarin, V. B., Seinfeld, J. H., and Yoo, K. Y.: A new inorganic atmospheric aerosol phase equilibrium model (UHAERO), Atmos. Chem. Phys., 6, 975-992, doi:10.5194/acp-6-975-2006, 2006.

Ansari, A. S. and Pandis, S. N.: An analysis of four models predicting the partitioning of semivolatile inorganic aerosol components, Aerosol Sci. Tech., 31, 129-153, doi:10.1080/027868299304200, 1999.

Ansari, A. S. and Pandis, S. N.: The effect of metastable equilibrium states on the partitioning of nitrate between the gas and aerosol phases, Atmos. Environ., 34, 157-168, doi:10.1016/S13522310(99)00242-3, 2000.

Bassett, M. and Seinfeld, J. H.: Atmospheric equilibrium model of sulfate and nitrate aerosols, Atmos. Environ., 17, 2237-2252, doi:10.1016/0004-6981(83)90221-4, 1983.

Bassett, M. E. and Seinfeld, J. H.: Atmospheric equilibrium model of sulfate and nitrate aerosols - II. Particle size analysis, Atmos. Environ., 18, 1163-1170, doi:10.1016/0004-6981(84)90147-1, 1984.

Binkowski, F. S. and Shankar, U.: The Regional Particulate Matter Model: 1. Model description and preliminary results, J. Geophys. Res., 100, 26191, doi:10.1029/95JD02093, 1995.

Fountoukis, C. and Nenes, A.: ISORROPIA II: a computationally efficient thermodynamic equilibrium model for $\mathrm{K}^{+}$ $\mathrm{Ca}^{2+}-\mathrm{Mg}^{2+}-\mathrm{NH}_{4}{ }^{+}-\mathrm{Na}^{+}-\mathrm{SO}_{4}{ }^{2-}-\mathrm{NO}_{3}{ }^{-}-\mathrm{Cl}^{-}-\mathrm{H}_{2} \mathrm{O}$ aerosols, Atmos. Chem. Phys., 7, 4639-4659, doi:10.5194/acp-7-46392007, 2007.

Hauglustaine, D. A., Balkanski, Y., and Schulz, M.: A global model simulation of present and future nitrate aerosols and their direct radiative forcing of climate, Atmos. Chem. Phys., 14, 1103111063, doi:10.5194/acp-14-11031-2014, 2014.
Jacobson, M. Z.: Studying the effects of calcium and magnesium on size-distributed nitrate and ammonium with EQUISOLV II, Atmos. Environ., 33, 3635-3649, doi:10.1016/S13522310(99)00105-3, 1999.

Jacobson, M. Z., Lu, R., Turco, R. P., and Toon, O. B.: Development and application of a new air pollution modeling system part I: Gas-phase simulations, Atmos. Environ., 30, 1939-1963, doi:10.1016/1352-2310(95)00139-5, 1996.

Kim, Y. P. and Seinfeld, J. H.: Atmospheric gas-aerosol equilibrium: III. Thermodynamics of crustal elements $\mathrm{Ca}^{2+}, \mathrm{K}^{+}$, and $\mathrm{Mg}^{2+}$, Aerosol Sci. Tech., 22, 93-110, doi:10.1080/02786829408959730, 1995.

Kim, Y. P., Seinfeld, J. H., and Saxena, P.: Atmospheric gas-aerosol equilibrium II. Analysis of common approximations and activity coefficient calculation methods, Aerosol Sci. Tech., 19, 182-198, doi:10.1080/02786829308959629, 1993a.

Kim, Y. P., Seinfeld, J. H., and Saxena, P.: Atmospheric gas-aerosol equilibrium I. Thermodynamic model, Aerosol Sci. Tech., 19, 157-181, doi:10.1080/02786829308959628, 1993 b.

Lelieveld, J., Berresheim, H., Borrmann, S., Crutzen, P. J., Dentener, F. J., Fischer, H., Feichter, J., Flatau, P. J., Heland, J., Holzinger, R., Korrmann, R., Lawrence, M. G., Levin, Z., Markowicz, K. M., Mihalopoulos, N., Minikin, A., Ramanathan, V., de Reus, M., Roelofs, G. J., Scheeren, H. A., Sciare, J., Schlager, H., Schultz, M., Siegmund, P., Steil, B., Stephanou, E. G., Stier, P., Traub, M., Warneke, C., Williams, J., and Ziereis, H.: Global air pollution crossroads over the Mediterranean, Science, 298, 794-799, doi:10.1126/science.1075457, 2002.

Lide, D. R.: Chemical Rubber Company (CRC): Handbook of Chemistry and Physics, 86th Edn., Taylor and Francis Group LLC, CD-ROM version, 2006, 2004-2005.

Makar, P., Bouchet, V., and Nenes, A.: Inorganic chemistry calculations using HETV - a vectorized solver for the $\mathrm{SO}_{4}^{2-}-\mathrm{NO}^{3-}-$ $\mathrm{NH}^{4+}$ system based on the ISORROPIA algorithms, Atmos. Environ., 37, 2279-2294, doi:10.1016/S1352-2310(03)00074-8, 2003.

Meng, Z., Seinfeld, J. H., Saxena, P., and Kim, Y. P.: Atmospheric gas-aerosol equilibrium: IV. Thermodynamics of carbonates, Aerosol Sci. Tech., 23, 131-154, doi:10.1080/02786829508965300, 1995.

Metzger, S. and Lelieveld, J.: Reformulating atmospheric aerosol thermodynamics and hygroscopic growth into fog, haze and clouds, Atmos. Chem. Phys., 7, 3163-3193, doi:10.5194/acp-73163-2007, 2007.

Metzger, S., Dentener, F., and Lelieveld, J.: Aerosol multiphase equilibrium composition: results of a parameterization applied to a global chemistry/tracer transport model, J. Aerosol Sci., 30, S877, doi:10.1016/S0021-8502(99)80449-2, 1999.

Metzger, S., Dentener, F., Pandis, S., and Lelieveld, J.: Gas/aerosol partitioning: 1. A computationally efficient model, J. Geophys. Res., 107, 16-1-24, doi:10.1029/2001JD001102, 2002a.

Metzger, S., Dentener, F., Krol, M., Jeuken, A., and Lelieveld, J.: Gas/aerosol partitioning: 2. Global modeling results, J. Geophys. Res., 107, ACH 17-1-ACH 17-23, doi:10.1029/2001JD001103, 2002b.

Metzger, S., Mihalopoulos, N., and Lelieveld, J.: Importance of mineral cations and organics in gas-aerosol partitioning of reactive nitrogen compounds: case study based on MINOS results, 
Atmos. Chem. Phys., 6, 2549-2567, doi:10.5194/acp-6-25492006, 2006.

Metzger, S., Steil, B., Xu, L., Penner, J. E., and Lelieveld, J.: New representation of water activity based on a single solute specific constant to parameterize the hygroscopic growth of aerosols in atmospheric models, Atmos. Chem. Phys., 12, 5429-5446, doi:10.5194/acp-12-5429-2012, 2012.

Nenes, A., Pandis, S. N., and Pilinis, C.: ISORROPIA: a new thermodynamic equilibrium model for multiphase multicomponent inorganic aerosols, Aquat. Geochem., 4, 123-152, 1998.

Nenes, A., Pandis, S. N., and Pilinis, C.: Continued development and testing of a new thermodynamic aerosol module for urban and regional air quality models, Atmos. Environ., 33, 15531560, doi:10.1016/S1352-2310(98)00352-5, 1999.

Pilinis, C. and Seinfeld, J. H.: Continued development of a general equilibrium model for inorganic multicomponent atmospheric aerosols, Atmos. Environ., 21, 2453-2466, doi:10.1016/00046981(87)90380-5, 1987.

Pilinis, C., Capaldo, K. P., Nenes, A., and Pandis, S. N.: MADMA New Multicomponent Aerosol Dynamics Model, Aerosol Sci. Tech., 32, 482-502, doi:10.1080/027868200303597, 2000.

Pringle, K. J., Tost, H., Message, S., Steil, B., Giannadaki, D., Nenes, A., Fountoukis, C., Stier, P., Vignati, E., and Lelieveld, J.: Description and evaluation of GMXe: a new aerosol submodel for global simulations (v1), Geosci. Model Dev., 3, 391-412, doi:10.5194/gmd-3-391-2010, 2010a.

Pringle, K. J., Tost, H., Metzger, S., Steil, B., Giannadaki, D., Nenes, A., Fountoukis, C., Stier, P., Vignati, E., and Lelieveld, J.: Corrigendum to "Description and evaluation of GMXe: a new aerosol submodel for global simulations (v1)" published in Geosci. Model Dev., 3, 391-412, 2010, Geosci. Model Dev., 3, 413-413, doi:10.5194/gmd-3-413-2010, 2010 b.

Salisbury, G., Williams, J., Holzinger, R., Gros, V., Mihalopoulos, N., Vrekoussis, M., Sarda-Estève, R., Berresheim, H., von Kuhlmann, R., Lawrence, M., and Lelieveld, J.: Groundbased PTR-MS measurements of reactive organic compounds during the MINOS campaign in Crete, July-August 2001, Atmos. Chem. Phys., 3, 925-940, doi:10.5194/acp-3-925-2003, 2003.

Saxena, P., Belle Hudischewskyj, A., Seigneur, C., and Seinfeld, J. H.: A comparative study of equilibrium approaches to the chemical characterization of secondary aerosols, Atmos. Environ., 20, 1471-1483, doi:10.1016/0004-6981(86)90019-3, 1986.

Seinfeld, J. H. and Pandis, S. N.: Atmospheric Chemistry and Physics: From Air Pollution to Climate Change, 1st Edn., J. Wiley, Hoboken, N.J., 1998.
Seinfeld, J. H. and Pandis, S. N.: Atmospheric Chemistry and Physics: From Air Pollution to Climate Change, 2nd Edn., J. Wiley, Hoboken, N.J., 2006.

Topping, D. O., McFiggans, G. B., and Coe, H.: A curved multicomponent aerosol hygroscopicity model framework: Part 1 - Inorganic compounds, Atmos. Chem. Phys., 5, 1205-1222, doi:10.5194/acp-5-1205-2005, 2005a.

Topping, D. O., McFiggans, G. B., and Coe, H.: A curved multicomponent aerosol hygroscopicity model framework: Part 2 - Including organic compounds, Atmos. Chem. Phys., 5, 1223-1242, doi:10.5194/acp-5-1223-2005, 2005b.

Wexler, A. and Potukuchi, S.: Kinetics and thermodynamics of tropospheric aerosols, in: Atmospheric Particles, edited by: Harrison, R. M. and Van Grieken, R., Wiley, Sussex, England, 203$231,1998$.

Wexler, A. S. and Clegg, S. L.: Atmospheric aerosol models for systems including the ions $\mathrm{H}^{+}, \mathrm{NH}_{4}^{+}, \mathrm{N}^{+}, \mathrm{SO}_{4}^{2-}, \mathrm{NO}_{3}^{-}, \mathrm{Cl}^{-}$, $\mathrm{Br}^{-}$, and $\mathrm{H}_{2} \mathrm{O}$, J. Geophys. Res., 107, ACH 14-1-ACH 14-14, doi:10.1029/2001JD000451, 2002.

Wexler, A. S. and Seinfeld, J. H.: Second-generation inorganic aerosol model, Atmos. Environ. A-Gen., 25, 2731-2748, doi:10.1016/0960-1686(91)90203-J, 1991.

Xu, L., Penner, J. E., Metzger, S., and Lelieveld, J.: A comparison of water uptake by aerosols using two thermodynamic models, Atmos. Chem. Phys. Discuss., 9, 9551-9595, doi:10.5194/acpd9-9551-2009, 2009.

Zaveri, R. A., Easter, R. C., and Wexler, A. S.: A new method for multicomponent activity coefficients of electrolytes in aqueous atmospheric aerosols, J. Geophys. Res., 110, D02201, doi:10.1029/2004JD004681, 2005.

Zhang, K. and Wexler, A.: Modeling urban and regional aerosols - Development of the UCD Aerosol Module and implementation in CMAQ model, Atmos. Environ., 42, 3166-3178, doi:10.1016/j.atmosenv.2007.12.052, 2008.

Zuend, A., Marcolli, C., Booth, A. M., Lienhard, D. M., Soonsin, V., Krieger, U. K., Topping, D. O., McFiggans, G., Peter, T., and Seinfeld, J. H.: New and extended parameterization of the thermodynamic model AIOMFAC: calculation of activity coefficients for organic-inorganic mixtures containing carboxyl, hydroxyl, carbonyl, ether, ester, alkenyl, alkyl, and aromatic functional groups, Atmos. Chem. Phys., 11, 9155-9206, doi:10.5194/acp11-9155-2011, 2011. 